\title{
Gene expression patterns associated with blood-feeding in the malaria mosquito Anopheles gambiae
}

\author{
Ali N Dana ${ }^{\dagger 1}$, Young S Hong ${ }^{\dagger 1,3}$, Marcia K Kern ${ }^{1}$, Maureen E Hillenmeyer ${ }^{1}$, \\ Brent W Harker ${ }^{1}$, Neil F Lobo ${ }^{1}$, James R Hogan${ }^{1}$, Patricia Romans ${ }^{2}$ and \\ Frank H Collins*1
}

Address: ${ }^{1}$ Center for Tropical Disease Research and Training, Department of Biological Sciences, University of Notre Dame, Notre Dame, IN 46556 , USA, ${ }^{2}$ Department of Zoology, University of Toronto, Toronto, ON M5S 3G5, Canada and ${ }^{3}$ Department of Tropical Medicine, Tulane University, New Orleans, LA 70112, USA

Email: Ali N Dana - adana@iupui.edu; Young S Hong - young@tulane.edu; Marcia K Kern - mkern@nd.edu; Maureen E Hillenmeyer - maureenh@stanford.edu; Brent W Harker - harker.1@nd.edu; Neil F Lobo - nlobo@nd.edu; James R Hogan - jhogan1@nd.edu; Patricia Romans - victorie@zoo.utoronto.ca; Frank H Collins* - frank@nd.edu

* Corresponding author †Equal contributors

Published: 14 January 2005

BMC Genomics 2005, 6:5 doi:10.1 |86/147|-2/64-6-5
Received: 05 August 2004

Accepted: 14 January 2005

This article is available from: http://www.biomedcentral.com/l47/-2/64/6/5

(C) 2005 Dana et al; licensee BioMed Central Ltd.

This is an Open Access article distributed under the terms of the Creative Commons Attribution License (http://creativecommons.org/licenses/by/2.0), which permits unrestricted use, distribution, and reproduction in any medium, provided the original work is properly cited.

\begin{abstract}
Background: Blood feeding, or hematophagy, is a behavior exhibited by female mosquitoes required both for reproduction and for transmission of pathogens. We determined the expression patterns of 3,068 ESTs, representing 2,000 unique gene transcripts using cDNA microarrays in adult female Anopheles gambiae at selected times during the first two days following blood ingestion, at 5 and 30 min during a 40 minute blood meal and at $0,1,3,5,12,16,24$ and 48 hours after completion of the blood meal and compared their expression to transcript levels in mosquitoes with access only to a sugar solution.
\end{abstract}

Results: In blood-fed mosquitoes, 413 unique transcripts, approximately $25 \%$ of the total, were expressed at least two-fold above or below their levels in the sugar-fed mosquitoes, at one or more time points. These differentially expressed gene products were clustered using $k$-means clustering into Early Genes, Middle Genes, and Late Genes, containing 144, 130, and 139 unique transcripts, respectively. Several genes from each group were analyzed by quantitative real-time PCR in order to validate the microarray results.

Conclusion: The expression patterns and annotation of the genes in these three groups (Early, Middle, and Late genes) are discussed in the context of female mosquitoes' physiological responses to blood feeding, including blood digestion, peritrophic matrix formation, egg development, and immunity.

\section{Background}

Hematophagy, blood-feeding, is a behavior exhibited by most arthropod vectors of human pathogens. In anautogenous mosquitoes, the female generally feeds to repletion on a single blood meal and then proceeds to use this nutrition as the basis for the development of a batch of eggs. The cycle of host seeking, blood feeding, egg development, and oviposition is generally called the 
gonotrophic cycle, a term coined by Beklemishev in 1940 [1]. For most mosquitoes living in optimal field or laboratory conditions, this cycle requires about forty-eight hours and involves a complex series of biological events, including peritrophic matrix formation, blood digestion, oocyte development, vitellogenesis, and excretion.

Digestion of the proteinaceous blood meal is required for oocyte development and vitellogenesis, and consequently these are coordinated processes. Multiple hormones interact to alter tissue states and to activate genes involved in these processes. The two hormones juvenile hormone (JH) and 20-hydroxyecdysone (20-E) are most fundamental to ovarian development. Within several days after emergence of female mosquitoes from the puparium, juvenile hormone $(\mathrm{JH})$ stimulates the separation of ovarian follicles from germaria and limited growth of the ovarian follicle to its pre-vitellogenic resting state [2]. JH also confers competence to fat body cells and ovarian follicles for uptake of ecdysteroidogenic hormone (OEH). Then, in response to a blood meal, gonadotrophins are released from cerebral neurosecretory cells and cause the ovaries to become OEH-responsive [3]. OEH stimulates the ovaries to secrete ecdysone, the precursor to 20-E, as well as 20-E during vitellogenesis [4-6]. Fat body cells take up ecdysone, convert it to 20-E and use it to activate transcription of vitellogenin genes [7], the genes encoding the major egg-yolk proteins, as well as a large number of other genes, many of whose products will be incorporated into eggs [see $[8,9]$ for reviews].

Prior to the blood meal, female mosquitoes access sugars for nutritional sustenance. During the first several hours following a blood meal, the mosquito undergoes physiological changes in addition to hormonal ones. Acquisition of a blood meal stimulates midgut proteolytic activity such that approximately $80 \%$ of the protein content is digested within one day [10-14]. Serine proteases including trypsins and chymotrypsins are responsible for the majority of endoproteolytic activity $[11,12,15]$. The role of trypsins in blood digestion has been well documented in Aedes aegypti, and more recently it has been investigated in An. gambiae. Despite the digestive proteolysis peak at 24 hours post blood meal, digestive enzymes exhibit two phases of transcription $[16,17]$. In Ae. aegypti there are three trypsins, early trypsin, which is constitutively expressed prior to blood feeding and two late trypsins which are blood induced. These two types of trypsins are also found in An. gambiae. The An. gambiae trypsin family includes seven genes clustered within $11 \mathrm{~kb}$ on chromosome 3R, in division 30A, that encode five functional proteins [18]. Trypsins 1 and 2 are both induced by a blood meal and exhibit similar expression profiles. In contrast to Trypsins 1 and 2, Trypsins 3, 4, and 7 are constitutively expressed in unfed females [18]. Trypsins 3 and 7 are down-regulated following a blood meal and not expressed again at levels detectable by RT-PCR until 28 hours post blood meal [18]. In addition to the trypsins, three chymotrypsin genes have been isolated and characterized in An. gambiae, two of which are located in tandem on chromosome 2L, in division 25D [19,20]. Both of these genes, AnChym 1 and 2, are expressed in the midgut by 12 hours post blood meal and their transcripts are abundant until 48 hours, as determined by PCR, unlike the levels of Trypsins 1 and 2 that have decreased dramatically by this time [19]. In contrast, the other characterized chymotrypsin, AgChyL, exhibits transcript level changes more similar to those of Trypsins 3-7 [20].

Two types of exopeptidases, carboxypeptidases and aminopeptidases, have been characterized in Anopheline mosquitoes. Edwards et al. [21] cloned a carboxypeptidase that was rapidly induced in An. gambiae midguts following blood meal ingestion. Multiple aminopeptidases have been isolated from hematophagous insects, and it has been suggested that they may play different roles in digestion [22-25]. Additional enzymes including glycosidases and lipases are also required for the digestion of non-proteinaceous blood constituents [26,27].

In addition to dramatic changes in physiology, blood feeding also induces changes in mosquito morphology. Following gut distension by blood ingestion, midgut epithelial cells secrete a Type I peritrophic matrix (PM) that is continuous along the length of the midgut $[14,28,29]$. Prior to the blood meal, the midgut epithelial cells contain high concentrations of apically located, morphologically granular, secretory vesicles. Presumably these apical granules contain precursors of the peritrophic matrix: as early as an hour after the adult female has taken a blood meal, they are no longer detectable [Staubli et al., 1966, as cited in [30]]. In An. gambiae, the PM can be visualized by electron microscopy as early as 12 hours PBM and it is fully formed by 48 hours PBM $[28,31]$. The PM is a biochemically complex structure containing not only chitin and other proteoglycans, but as many as 20-40 different proteins [31-33]. However, only one gene encoding a peritrophic matrix protein has been cloned in An. gambiae [34]. The exact functions of the PM remain unknown, but it has been suggested that this semi-permeable porous structure may function as a restrictive layer protecting the midgut epithelium from proteolytic digestive enzymes, from haematin crystals that form following hemoglobin breakdown and as a barrier to blood-borne pathogens including bacteria and malaria parasites [reviewed in [35]].

Once the adult mosquito acquires a blood meal, she spends approximately 48 hours converting about $20 \%$ of it into egg constituents [36], using another fraction of it to 
support the intense biosynthetic activities of this period and defecating the rest. Oogenesis in the mosquito ovary actually begins post-eclosion but oocyte growth attenuates at a resting stage until blood meal ingestion. Once reinitiated, egg development continues until oviposition. Successful egg production not only requires ovarian events for development and maturation of oocytes, but also synthesis of yolk constituents, both protein and lipid, in the fat body, followed by their uptake by oocytes and storage for later use during embryogenesis. Collectively, the events of yolk synthesis, uptake and storage constitute the process of vitellogenesis [30]. Vitellogenesis and oogenesis require the coordination of molecular events in at least these two different abdominal tissues, the fat body and ovary. Based on morphological and physiological criteria, the ovarian cycle can be divided into four phases: 1) Pre-vitellogenic, 2) Initiation, 3) Trophic, and 4) Posttrophic Phase [30].

The meroistic ovary of An. gambiae contains approximately 50 functional egg-production structures, the ovarioles. Each ovariole is comprised of two parts, a distal germarium and a vitellarium proximal to a common oviduct through which eggs will pass as they are laid. In the germarium, mitosis of the primordial germ cells creates a syncitium with an oocyte and seven nurse cells interconnected by intracellular bridges, or ring canals as a result of incomplete cytokinesis. Both the germ cell and the nurse cells are surrounded by a somatically derived follicular epithelium [37-39]. The first pre-vitellogenic phase is completed within three days of eclosion and ends with the separation of these follicles from the germaria and entry into the vitellaria. At the end of this phase, oocytes may have undergone some growth but then arrest until events initiated by acquisition of a blood meal cause them to become competent for ovarian vitellogenic events.

Ingestion of a blood meal reinitiates ovarian development and follicle growth resumes. In Ae. aegypti and Anopheles albimanus, this period appears variable, lasting 3-10 and 8-16 hours, respectively, and ends with the initiation of vitellogenin synthesis [30]. In the next two days, during the trophic phase, the mosquito generates large amounts of vitellogenin, the secreted precursor to the major yolk protein vitellin. In addition to vitellogenin, the developing oocytes also accumulate other proteins, and lipids from the hemolymph, as well as ribosomes and mRNAs synthesized in the syncitial nurse cells. These latter constituents are transported to the germ cell through the ring canals connecting the oocytes and nurse cells by a process of cytoplasmic streaming [40]. Following delivery, several maternal mRNAs become localized within the oocyte. These maternal transcripts are fundamental for dorsal/ ventral and anterior/posterior patterning of the embryo that will develop from the oocyte. This pattern of deposi- tion and the patterning of the eggshell also depend on a complex signaling process involving both the somatic cells of the follicular epithelium and the oocyte.

Once oocyte growth has ceased, vitellogenin synthesis terminates. This signals the onset of the post-trophic phase. During this time, the oocytes mature and eggshell structures begin to develop. The chorion, part of the eggshell, is secreted by the follicular epithelium and contains two layers, the first secreted, inner endochorion and the later secreted, outer exochorion [30]. It is the endochorionic layer that will harden and melanize after oviposition.

Specialization of eggshell structures necessitates communication between cells. The RAS 1 signaling cascade is an important means of communication during the processes of oocyte and eggshell patterning, as it is during eye development and differentiation of structures late in embryogenesis [41,42]. During patterning in Drosophila, developing oocytes produce the TGF $\alpha$ protein Gurken that binds to the epidermal growth factor receptor (EGFR), a receptor tyrosine kinase (RTK) localized to the posterior follicle cells, to initiate RAS 1 signaling. Downstream from the activation of this RTK, the GTP-binding protein RAS 1 initiates a series of enzymatic events propagated successively by three protein kinases, RAF, MAPK, and MAPK kinase (MEK), resulting in the translocation of nuclear factors and possibly the concomitant reorganization of the cytoskeleton [reviewed in [43]]. Thus, a cascade of events leads to the establishment of the posterior follicle cell fate. The posterior follicle cells then signal back to the germ cells. This results in the reorganization of the oocyte cytoskeleton, and regulates the localization of anterior/posterior determinants. Similar to the eggshell, the oocyte also undergoes dorsal-ventral patterning. Following patterning of the follicle cells, maternal gene products are regulated by the Toll signaling pathway to generate a transcription factor gradient that will spatially regulate activity of specific zygotic genes within the fertilized oocytes [44].

Vitellogenic events in the fat body have also been divided into phases: 1) Pre-vitellogenic, 2) Vitellogenic, and 3) Termination. The pre-vitellogenic phase in the fat body coincides with the pre-vitellogenic phase of the ovarian cycle. During this phase, RNA synthesis increases in the fat body and the rough endoplasmic reticulum and the Golgi complex proliferate to prepare for the production of vitellogenin. At the start of the vitellogenic phase, the release of mosquito hormones initiated by digestion signal the onset of vitellogenesis [45]. Synthesis of large amounts of vitellogenins is facilitated by the large quantities of biosynthetic machinery generated during pre-vitellogenic stages, but also depends on the presence of multiple vitellogenin genes (Romans, unpublished). Following 
Table I: Microarray composition

\begin{tabular}{lc}
\hline Controls & Clones \\
\hline $\begin{array}{l}\text { Negative Controls } \\
\text { Positive Controls }\end{array}$ & 108 \\
\hline Libraries & 3 \\
\hline $\begin{array}{l}\text { Sugar-fed Adult Female (incubated } 30 \text { hours at } 19^{\circ} \mathrm{C} \text { ) Abdomen library } \\
\left.\text { Blood-fed Adult Female (incubated } 30 \text { hours PBM at } 19^{\circ} \mathrm{C}\right) \text { Abdomen library }\end{array}$ & 1132 \\
Plasmodium berghei Blood-fed Adult Female (incubated 30 hours PBM at $19^{\circ} \mathrm{C}$ ) Abdomen library & 721 \\
\hline Total & 1204 \\
\hline
\end{tabular}

synthesis, vitellogenin is released into the hemolymph and eventually diffuses through channels between the cells of the follicular epithelium, whereupon it is accumulated by the oocytes by a process of receptor-mediated endocytosis in clathrin-coated pits [8]. When vitellogenesis has ceased, during the termination phase, the biosynthetic machinery in the fat body is degraded via a lysosomal pathway, at least in Ae. aegypti [46].

Thus, blood feeding initiates a complex series of physiological events in at least three tissues that are integrated by the actions of $\mathrm{JH}, 20-\mathrm{E}$ and peptide hormones. These events may be required for parasite development; they certainly can be modulated by the presence of parasites $[47,48]$ and may provide points of intervention for mosquito control. Microarray analysis provides a tool to study global expression patterns of thousands of genes simultaneously. By comparing the level of transcription of a gene over time between two states, e.g. blood-fed $v$ s. sugar-fed, an expression signature for each gene can be defined in response to blood feeding. Consequently, these expression patterns may indicate how these genes are regulated and interact, and also the biological processes in which the act. In this study we performed microarray analysis of genes in female mosquito abdomens during the first 48 hours after a blood meal. We have implicated many of these genes in different processes stimulated de novo by blood feeding. The elucidation of the expression profiles of abdominal genes will provide a broadened basis for understanding vector-parasite interactions. Our study certainly provides insights into the physiology of the malaria vector Anopheles gambiae.

\section{Results \\ Array composition}

Microarray analysis was conducted on 3057 cDNA clones generated from three different adult female An. gambiae mosquito abdomen-derived cDNA libraries to elucidate major patterns of gene expression through 48 hours post ingestion of a blood meal. Arrays were constructed from triplicate spotted negative controls (purified water, $3 \times$ SSC with no DNA, and empty wells), positive controls for blood-fed samples consisting of 3 clones whose ESTs corresponded to rat $(R$. norvegicus) $\alpha$ and $\beta$ hemoglobin chains, and PCR-amplified fragments obtained from 1132,721 , and 1204 clones randomly picked from the sugar-fed (harvested after 30 hours at $19^{\circ} \mathrm{C}$ ), rat bloodfed (harvested 30 hours $\mathrm{PBM}$ at $19^{\circ} \mathrm{C}$ ), and P. berghei infected rat blood-fed (harvested 30 hours PBM at $19^{\circ} \mathrm{C}$ ) abdomen libraries, respectively (Table 1 ). Approximately $84 \%$ of PCR-amplified fragments were visualized on ethidium bromide stained $1 \%$ agarose, $1 \times$ TBE gels prior to spotting (data not shown). Of these PCR-amplified fragments, 2219 clones (87\% of electrophoresed PCR products) were represented by a single defined band (Table 2).

ESTs corresponding to these spotted cDNAs were screened for mitochondrial contamination, filtered based on sequence trace file quality, and assembled (EST clustered) using the DNAstar Seqman II software (DNAstar, CA) (Table 3). The high quality ESTs clustered into 491 contigs (consensus sequence generated from $\geq 2$ overlapping ESTs) and 1415 singletons (ESTs with no sequence similarity to any other EST in the assembly) for a total of 1906 unique transcripts (Table 4).

\section{Microarray and bioinformatic analyses}

Global patterns of greater than two-fold up-regulation or down-regulation for these cDNAs were established by comparing transcript levels in blood-fed An. gambiae adult females at ten time points during and post ingestion of a blood meal to the levels in sugar-fed females. First strand cDNA was generated from total RNA collected at $5 \mathrm{~min}$ and $30 \mathrm{~min}$ after initiation of blood feeding and at $0,1,3$, $5,12,24$, and $48 \mathrm{hr}$ post-blood meal. All cDNA populations were labeled and hybridized to arrays. For each PCRamplified insert, $\mathrm{Cy} 3$ and $\mathrm{Cy} 5$ fluorescent dye levels were 
Table 2: Appearance of PCR product following gel electrophoresis

\begin{tabular}{|c|c|c|c|c|c|}
\hline & Total Clones & Singlet & Doublet & Smear & No Product Visible \\
\hline Amplification of 2558 Clones & 2558 & $2098(82 \%)$ & $117(5 \%)$ & $6(<1 \%)$ & 337 (13\%) \\
\hline $\begin{array}{l}\text { Re-amplification of I } 83 \text { Clones previously } \\
\text { amplified with "No Product Visible" }\end{array}$ & 183 & $121(66 \%)$ & $14(8 \%)$ & 0 & $48(26 \%)$ \\
\hline Cumulative & 2558 & $2219(87 \%)$ & $|3|(5 \%)$ & $6(<1 \%)$ & 202 (8\%) \\
\hline
\end{tabular}

Note: PCR-amplified fragments were visualized on ethidium bromide stained I\% agarose, I $\times$ TBE gels. Approximately I3\% of PCR products could not be visualized following the first amplification due to product yield below the threshold of ethidium bromide detection; 54\% of these (I83) were re-amplified.

Table 3: EST composition of array

\begin{tabular}{lcc}
\hline & Number & Percentage \\
\hline High Quality Sequence Data & 2707 & $88.56 \%$ \\
Poor Quality Sequence Data & 131 & $4.28 \%$ \\
Mitochondrial DNA & 222 & $7.25 \%$ \\
\hline Total & 3060 & $100 \%$ \\
\hline
\end{tabular}

Note: EST analysis includes the ESTs of the positive controls (Rattus norvegicus hemoglobin chains).

Table 4: Putative transcripts represented on the array following EST assembly

\begin{tabular}{lcc}
\hline & Number & ESTs Represented \\
\hline Contigs & 491 & 1292 \\
Singletons & 1415 & 1415 \\
\hline Total & 1906 & 2707 \\
\hline
\end{tabular}

Note: EST assembly includes the ESTs of the positive controls (Rattus norvegicus hemoglobin chains).

Table 5: Sequence similarity of consensus sequences

\begin{tabular}{|c|c|c|c|c|c|c|}
\hline & Blastn (WGS An. gambiae) & Blastx (Nr) & Blastn (Nr) & Blastn (dbEST) & Unannotated & Total \\
\hline 3 Positive Controls & No Significant Hit & 3 & & & & 3 \\
\hline 403 Unique Transcripts & 403 & 240 & 8 & 112 & 43 & 403 \\
\hline Early Genes & 144 & 77 & 2 & 45 & 20 & 144 \\
\hline Middle Genes & 130 & 78 & 6 & 36 & 10 & 130 \\
\hline Late Genes & 139 & 93 & 2 & 31 & 13 & 139 \\
\hline Total & 413 & 248 & 10 & 112 & 43 & 413 \\
\hline
\end{tabular}


measured from 3 replicate spots on each of 50 arrays to generate average signal intensities, and an expression ratio depicting transcript fold change between sugar-fed and blood-fed mosquitoes calculated. Following quality control filtering and normalization, $456 \mathrm{cDNAs}$ and the rat $\beta$ hemoglobin gene, the positive control, were expressed more than twofold above or below control, sugar-fed levels at one or more of the 10 blood-feeding time points. Following EST analysis, the $456 \mathrm{cDNAs}$ were found to represent 413 unique mosquito transcripts, 10 of which were present in more than one set. This anomaly is due to EST clustering of alternatively spliced transcripts with different expression patterns. More unique transcripts are up-regulated than down-regulated in response to blood feeding, while $10 \%$ of them are both up-regulated and down-regulated over the time course of this study: 192 are up-regulated at least twofold, 173 are down-regulated at least twofold, and 48 are down-regulated and up-regulated. Bioinformatic analyses of these 413 unique transcripts showed that all sequences shared sequence identity with the An. gambiae genome (Table 5), 90\% of which shared sequence identity with an entry in $\mathrm{Nr}$ of dbEST (Table 5). In this analysis Blast hits with an E value $\leq 1 \times 10^{-4}$ were considered significant.

\section{Microarray gene clustering and principal components analysis}

The behaviors of the gene products identified as at least twofold up/down-regulated were grouped into three sets using $k$-means clustering (Figure 1) and named according to the time of their induction during the 48-hour time course following the initiation of blood feeding. Set 1 , hereafter referred to as the "Early Genes", contains 144 unique transcripts derived from 152 cDNAs, which are expressed mainly during the early time points (Table 6, Figure 1A). The majority of these genes are appear induced at least twofold more abundantly than in sugar-fed mosquitoes during the first five minutes of blood feeding. Many of these transcripts remain induced until 1-hour PBM, although some remain induced until 5 hours PBM. After 5 hours post blood meal, the majority of Early Genes is down-regulated and they remain down-regulated even 48 hours after blood meal ingestion. A small subset of the Early Genes shows a variant pattern of gene expression in which the transcripts are up-regulated from the first 5 minutes of blood uptake through 1 hour PBM followed by a repression in expression from 3 to 24 hours PBM and then a greater than twofold induction at 48 hours PBM. The 130 unique transcripts represented by 147 cDNAs in Set 2, the "Middle Genes", follow a more dynamic pattern of gene expression than the Early Genes (Table 6 and Figure $1 \mathrm{~B}$ ). Most Middle Genes are down-regulated in bloodfed versus sugar-fed mosquitoes until 3 hours PBM followed by an increase in expression commencing at 5 hours PBM and peaking between 12 and 24 hours PBM.
Subsequently, Middle Genes are down-regulated to initial transcript abundances by 48 hours PBM. Also, in a behavior largely exhibited by the Middle Genes, approximately $40 \%$ of genes are down-regulated when the mosquitoes completed feeding and left the rat (0 hours PBM). Set 3, the "Late Genes" contains 139 unique transcripts, 157 cDNAs, which are either down-regulated or constitutively expressed until 12 to 16 hours PBM after which they are up-regulated and, in contrast to the Middle Genes, continue to be highly expressed even at 48 hours PBM (Table 6, Figure 1C).

Principal components analysis (PCA) of these 413 unique differentially expressed transcripts was also conducted to support the $k$-means defined sets. Following PCA, each transcript was plotted in a scatter plot comparing the PCA 1 and PCA 2 values. The three $k$-means-defined sets of genes did not overlap on these scatter plots. Thus the PCA results support classification of these transcripts into three groups. For each of the $k$-means defined groups, genes that had a PCA 1 or PCA 2 value greater than 0.5 or less than -0.5 were plotted on a parallel coordinates display (Figures 2 and 3). The resulting data sets contained 82, 69, and 98 unique transcripts representing Early Genes, Middle Genes, and Late Genes, respectively (Table 6).

\section{Gene annotation and gene ontology assignments}

To identify An. gambiae genes whose products are involved in related processes, the EST consensus sequences of the transcripts differentially expressed in these 3 patterns were annotated using sequence similarity and categorized using the molecular functions listed by the Gene Ontology Consortium (GOC) and the biological processes defined by Holt et al. [49]. Gene annotations for all 413 at least twofold differentially expressed gene products are given in the Supplementary Table S1. They were then categorized into 9 major categories with 31 subdivisions (Table 7). 48\% of the genes could not be annotated and therefore were categorized as "Unknown". The three most numerous categories containing annotated gene products were "Metabolism", "Protein Synthesis", and "Egg Production".

During the 48 hours PBM, the majority of gene products involved in metabolism were up-regulated Early and Middle Genes. Largely different metabolic biological processes were up-regulated in Early vs. Middle and Late Genes. More than half of the Early metabolic gene products, 20/29 unique transcripts, appear to be involved in carbohydrate metabolism, oxidative phosphorylation, and protein digestion. In contrast, $80 \%$ of the metabolic genes, 24/30 unique transcripts, represented in the Middle Genes contribute to various processes in protein digestion and metabolism, and metabolism of amino acids and their derivatives. One third of the Late genes involved 


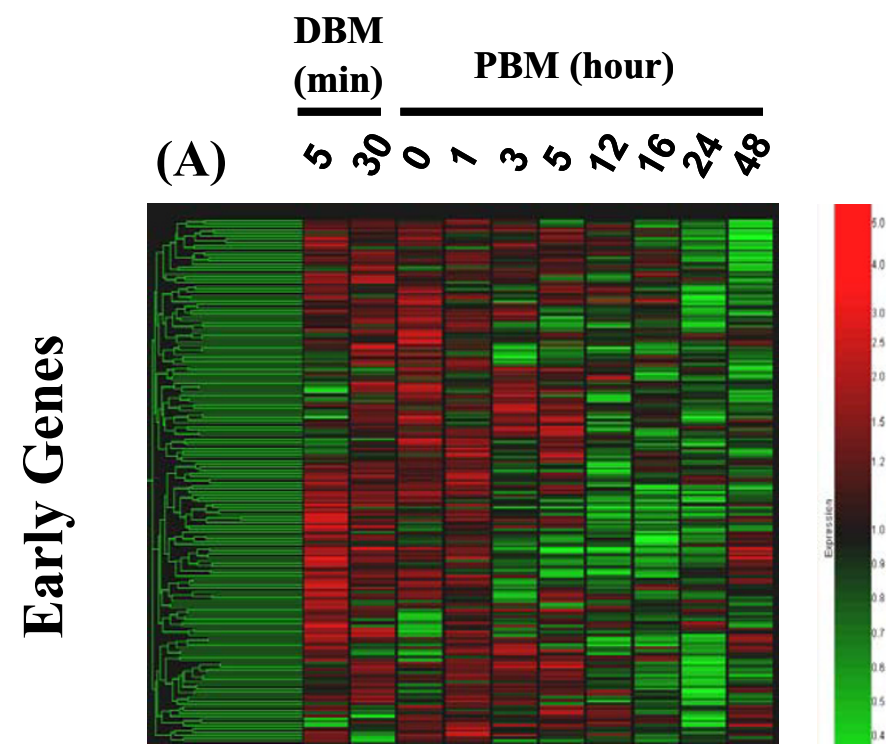

(B)

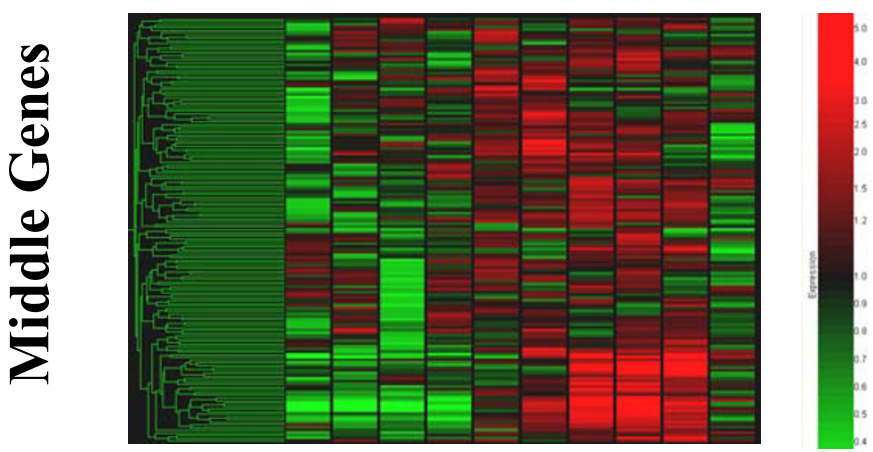

(C)

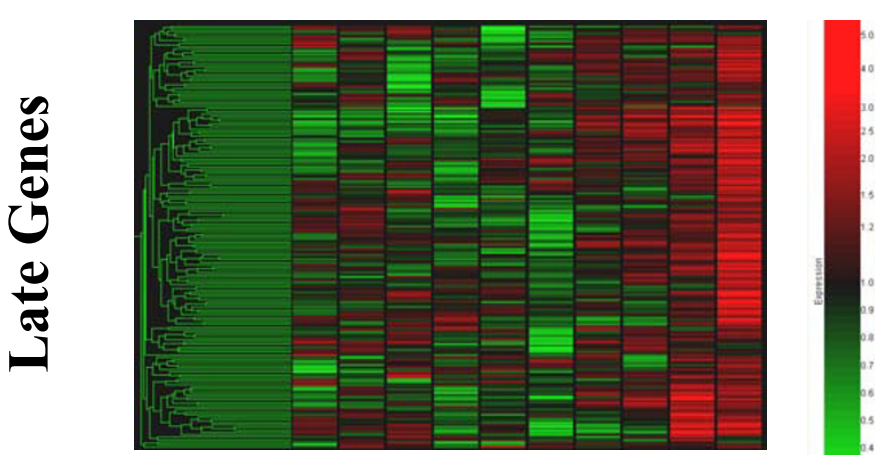

\section{Figure I}

Gene trees displaying the microarray generated expression profiles of abdomen-derived cDNAs in blood-fed compared to sugar-fed adult female mosquitoes during the following times: 5 and 30 minutes during blood meal (DBM), 0, I, 3, 5, 12, 16, 24, and 48 hours post blood meal (PBM). $k$-means clustering of all genes up-regulated and down-regulated at least two-fold during at least one of the ten time points generated three sets of genes. These $k$-means-derived groups of genes were hierarchically clustered for visualization and include Set I designated the Early Genes (A), Set 2 designated the Middle Genes (B), and Set 3 designated the Late Genes (C). Each gene is represented by a single row of colored boxes; each time point is represented as a single column of colored boxes. The expression scale is represented as a gradation of color ranging from 5 fold induced genes indicated by saturated red to 2.5 fold repressed genes indicated by saturated green. 
Table 6: Bioinformatic analysis of two-fold expressed genes

\begin{tabular}{|c|c|c|c|c|}
\hline & $\begin{array}{l}\text { Early } \\
\text { Genes }\end{array}$ & $\begin{array}{c}\text { Middle } \\
\text { Genes }\end{array}$ & $\begin{array}{l}\text { Late } \\
\text { Genes }\end{array}$ & Total \\
\hline Twofold Expressed cDNAs (represented by consensus sequences $>100$ bp in length) & 152 & 147 & 157 & 456 \\
\hline Replicate Consensus Sequences within k-means Sets & 8 & 17 & 18 & 43 \\
\hline Unique Transcripts & 144 & 130 & 139 & $403^{*}$ \\
\hline Unique Transcripts included within PCA Analysis & 82 & 69 & 98 & 249 \\
\hline
\end{tabular}

*The complete data set (Early, Middle and Late genes combined) contains 413 unique transcripts. However, ten transcripts are present in two different gene sets and were counted twice as a result.

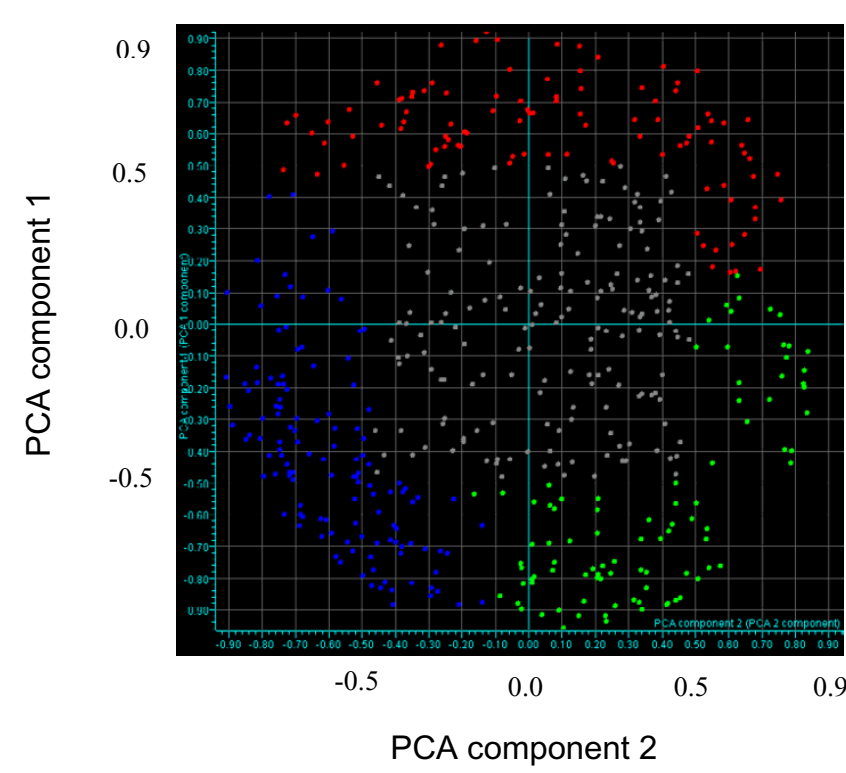

Figure 2

Scatter plot of the first two components for each gene that is either up-regulated or down-regulated at least two-fold during one time point in the course of this experiment. The Early Genes, Middle Genes, and Late Genes are colored red, blue and green, respectively. The genes colored in grey include Early, Middle and Late genes that did not have a value greater than 0.5 or less than -0.5 of both PCA I and PCA 2 components.

in metabolism, 8/25 unique transcripts, are involved in protein metabolism. Five of these annotated sequences, ASs 368, 807, 1179, 279, and 922, encode products involved in post-translational modification.

Reflecting the necessity of biosynthetic machinery in cell maintenance and growth, and probably also the highly conserved nature of proteins involved in housekeeping functions, the protein synthesis category contained the second largest number of genes functioning in a known process. 69\%, 11/16 unique transcripts and 53\%, 10/19 unique transcripts, respectively of the Early and Middle Genes, in this category are involved in translation. Approximately 25\%, 5/19 unique transcripts, and 40\%, 6/ 14 unique transcripts, of the protein synthesis genes represented among Middle and Late genes, are required for transcription and mRNA processing. This result seems almost paradoxical because transcription and mRNA processing necessarily precede translation.

A number of biological processes were related by their involvement in nuclear events or the overall activity of the cell. There were three times as many genes involved in cellular processes among the Late genes than in the other two sets combined. Although all the genes involved in the cell cycle are Middle and Late Genes, the most strikingly upregulated cellular process genes were those involved in chromatin assembly/disassembly. 5 of the 10 cellular process Late genes (ASs 1136, 59, 592, 1011, and 1792) are involved in maintenance of chromatin structure, a biological process represented only in the Late genes. These Late genes include both histones and high mobility group proteins.

The majority of significantly up and down regulated genes appear to function in egg production, either in the development and maturation of oocytes or in the fat body synthesis of products that will be deposited in oocytes. Almost $90 \%$ of them, 17/19 unique transcripts, are Middle and Late genes. These genes are described in detail in the Discussion section. In contrast, half of the genes categorized as cellular communication genes, 4/8 unique transcripts, are Early genes. The majority of the cellular communication gene products in the combined sets of Middle and Late genes, are involved in different signal transduction pathways. Additionally, almost half of the intra-/extracellular architecture maintenance genes are Early genes. This category includes a wide variety of gene products such as peritrophin, both muscle-related and cytoskeletal actins, $\alpha$-catenin and $\beta$-integrin. The Middle 

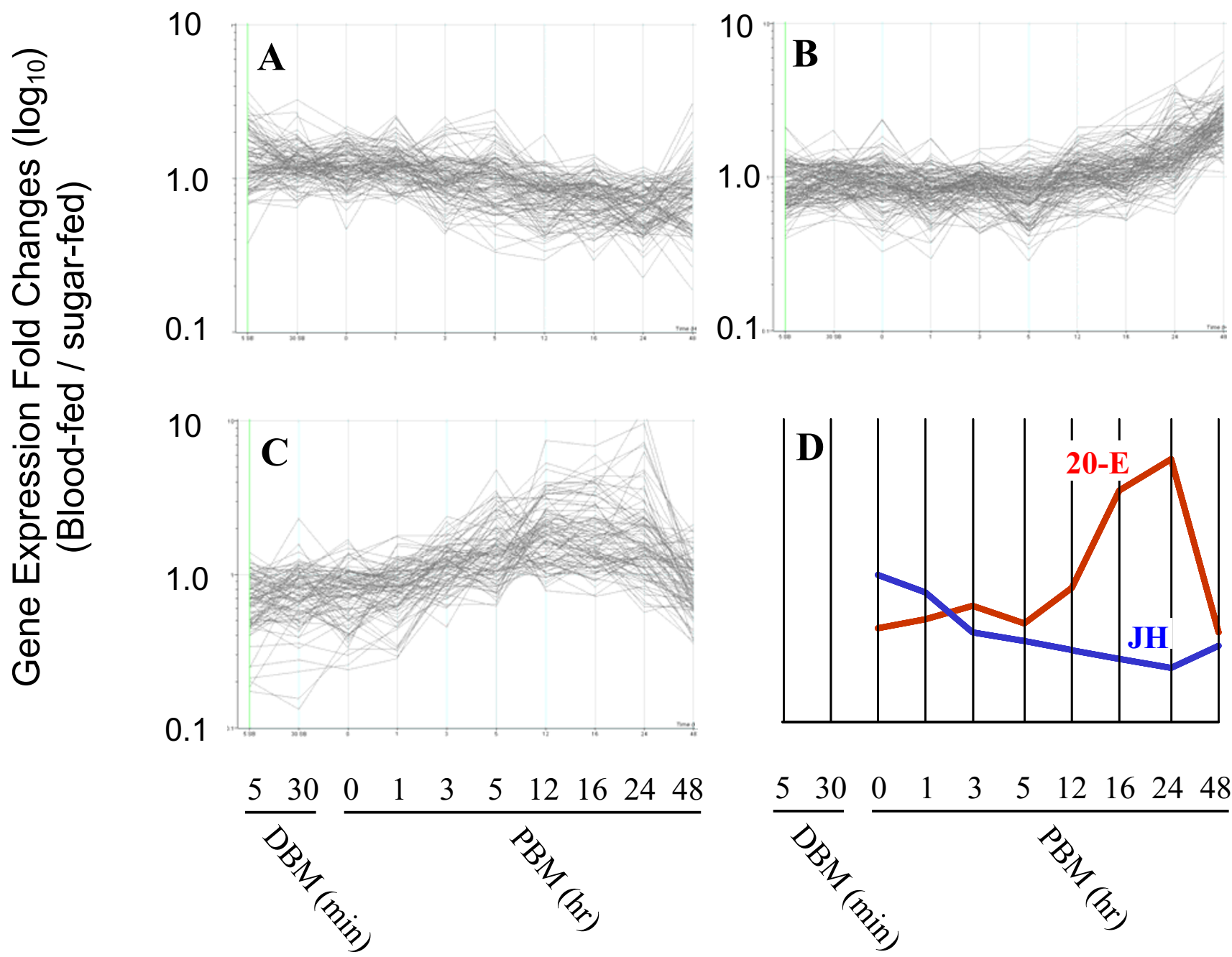

Figure 3

Parallel coordinates display of expression profiles of differentially expressed PCA-filtered genes from the Early Genes (A), Middle Genes (B), and Late Genes (C). X-axes correspond to a successive time point. $Y$-axes denote the ratio of fluorescent intensities of blood-fed to sugar-fed samples at each time point for each gene in Panels (A), (B), and (C). Plotted genes had a PCA I value greater than 0.5 or less than -0.5 , or a PCA 2 value greater than 0.5 or less than -0.5 . In Panel (D), the activity levels of juvenile hormone $(\mathrm{JH})$ and ecdysone $(20-\mathrm{E})$ are plotted on a similar parallel coordinate graph (modified from Dhadialla and Raikhel 1994).

and Late genes in this category were mainly structural and included two peritrophins (ASs 13 and 642).

The biological process categorized as transport included not only the movement of ions such as zinc, sodium and potassium, but also transport of molecules via receptormediated endocytosis. All three transport gene products, ASs 1336, 1605, and 432, in the Middle genes are responsible for the movement of ions. In contrast, in the Early and Late genes, several gene products (ASs 1974, 1071, and 2086) appear to be involved in receptor-mediated transport via clathrin-coated vesicles.

A number of genes responding to oxidative stress ( 6 genes in total) were found in all three sets of genes indicating that they are transcribed throughout the 48 hours PBM. 
Seven additional gene products most probably involved

Table 7: Functional annotation of AS represented by microarray expression group

\begin{tabular}{|c|c|c|c|}
\hline & Early & Middle & Late \\
\hline \multicolumn{4}{|l|}{ Metabolism } \\
\hline Simple/Complex Carbohydrate Metabolism and Transport & 3 & 0 & 2 \\
\hline Oxidative Phosphorylation & 8 & 5 & 1 \\
\hline Lysosomal Enzymatic Digestion & 0 & 0 & 2 \\
\hline Protein Digestion & 4 & 4 & 3 \\
\hline Protein Modification, Metabolism, Transport and Localization & 5 & 12 & 8 \\
\hline Amino Acid and Derivative Metabolism and Transport & I & 8 & 2 \\
\hline Nucleobase/Nucleoside/Nucleotide/Nucleic acid Metabolism and Transport & 4 & I & 3 \\
\hline Fatty Acid/Lipid Metabolism and Transport & 1 & 0 & 2 \\
\hline Vitamin/Vitamin Derivative/Cofactor Metabolism and Transport & 2 & 0 & 0 \\
\hline Xenobiotic Metabolism and Transport & 1 & 0 & 2 \\
\hline Total & 29 & 30 & 25 \\
\hline \multicolumn{4}{|l|}{ Transport } \\
\hline Ion Transport & 3 & 3 & 0 \\
\hline Receptor-mediated Endocytosis & I & 0 & 2 \\
\hline Total & 4 & 3 & 2 \\
\hline \multicolumn{4}{|l|}{ Protein Synthesis } \\
\hline Transcription and mRNA Processing & 2 & 5 & 6 \\
\hline Translation & 11 & 10 & 4 \\
\hline Protein Folding & 3 & 4 & 4 \\
\hline Total & 16 & 19 & 14 \\
\hline
\end{tabular}

\section{Cellular Processes}

\begin{tabular}{llll}
\hline Cell Cycle & 0 & 3 & 3 \\
Cellular Proliferation & 0 & 0 & 2 \\
Chromatin Assembly/Disassembly & 0 & 0 & 0 \\
Apoptosis & 1 & 0 & 0 \\
Senescence & 1 & 0 & 3 \\
\hline Total & 2 & 3
\end{tabular}

\section{Egg Production}

\begin{tabular}{|c|c|c|c|}
\hline Vitellogenesis/Oogenesis/Embryogenesis & 2 & 10 & 7 \\
\hline Melanization & 0 & 1 & 0 \\
\hline Total & 2 & 11 & 7 \\
\hline \multicolumn{4}{|l|}{ Cellular Communication } \\
\hline Signal Transduction & 1 & 1 & 2 \\
\hline Cell-cell Signaling & 3 & 0 & I \\
\hline Total & 4 & 1 & 3 \\
\hline
\end{tabular}


Table 7: Functional annotation of AS represented by microarray expression group (Continued)

\begin{tabular}{|c|c|c|c|}
\hline \multicolumn{4}{|c|}{ Intra-/Extra-cellular Architecture Maintenance } \\
\hline Structural & 3 & 4 & 2 \\
\hline Muscle-related & I & 0 & 0 \\
\hline Cell Adhesion & 1 & 1 & 0 \\
\hline Cytoskeleton Organization and Biogenesis & 1 & 0 & 2 \\
\hline Total & 6 & 5 & 4 \\
\hline \multicolumn{4}{|l|}{ Response to Stress/External Stimulus } \\
\hline Response to Oxidative Stress & 2 & 1 & 3 \\
\hline Immune/Defense Response & 2 & 2 & 3 \\
\hline Total & 4 & 3 & 6 \\
\hline \multicolumn{4}{|l|}{ Unknown } \\
\hline Total & 77 & 55 & 68 \\
\hline
\end{tabular}

in immunity, a response to external stress, were found among these three gene sets.

\section{qRT-PCR analysis}

Expression profiles of eight selected genes and the RP S7 control gene were confirmed using a quantitative realtime PCR strategy (Figure 4). Transcript levels for each of the eight genes were quantified using SYBR Green technology and differences in their expression between sugar-fed and blood-fed mosquitoes at 0, 5, 12, 24 and 48 hours PBM determined. Although the magnitudes of the changes in transcript abundances of all the genes whose expression levels were quantified by both techniques differed between the techniques, the changes in direction of expression, whether positive or negative, remained consistent for the majority of them. In addition, the overall patterns of expression exhibited by the three sets of genes were also apparent in the expression profiles created by qRT-PCR analysis. For the two Early genes, microarray analysis overestimated transcript levels between 2- and 30-fold more than qRT-PCR analysis. In contrast, for the majority of the Middle and Late gene expression measurements, microarray analysis underestimated transcript abundances relative to qRT-PCR analysis.

\section{Discussion}

We have determined the gene expression patterns of 3,068 abdomen-derived cDNAs from adult female An. gambiae mosquitoes representing 1906 unique transcripts were determined in the first two days following ingestion of a blood meal by microarray analysis. 413 unique transcripts were shown to be up-or down-regulated at least twofold in blood fed mosquitoes relative to sugar-fed mosquitoes at one or more of the following times: $5 \mathrm{~min}$ and $30 \mathrm{~min}$ following initiation of blood feeding and $0,1,3,5,12,24$, and $48 \mathrm{hr}$ post-blood meal. These transcripts were clustered into three sets with different temporal patterns of expression that may reflect the major hormonal changes occurring within the mosquito during a gonotrophic cycle. These differentially expressed gene products were annotated putatively using sequence similarity searches and categorized by biological process to identify the major events occurring post blood meal ingestion in the female mosquito.

Multiple hormones interact to alter tissue states and to activate genes involved in the female mosquito's digestion of a blood meal, in oocyte development and in vitellogenesis. The three sets of differentially transcribed genes discerned in this study, the Early, Middle and Late genes may reflect differential hormonal responsiveness. After acquisition of a blood meal, the transcript levels of the Early genes which were abundant during blood feeding showed general declines until 24 hours PBM, after which a subset of transcript levels began to rise again. Expression of Early genes may be linked to the relatively high titers of $\mathrm{JH}$ present at the beginning of the first gonotrophic cycle and may then be repressed as a result of declining $\mathrm{JH}$ titers or of increasing 20-E. The expression of Middle gene transcripts followed an expression pattern that reflects the titers of 20-E: levels sharply increased by 12 hours PBM, remained stable or increased only slightly until 24 hours PBM, and then declined rapidly. OEH secreted by median neurosecretory cells stimulates the ovaries to secrete 20-E during vitellogenesis and the activity of this hormone begins to rise by 3-5 hours, peaks between 12 and 24 

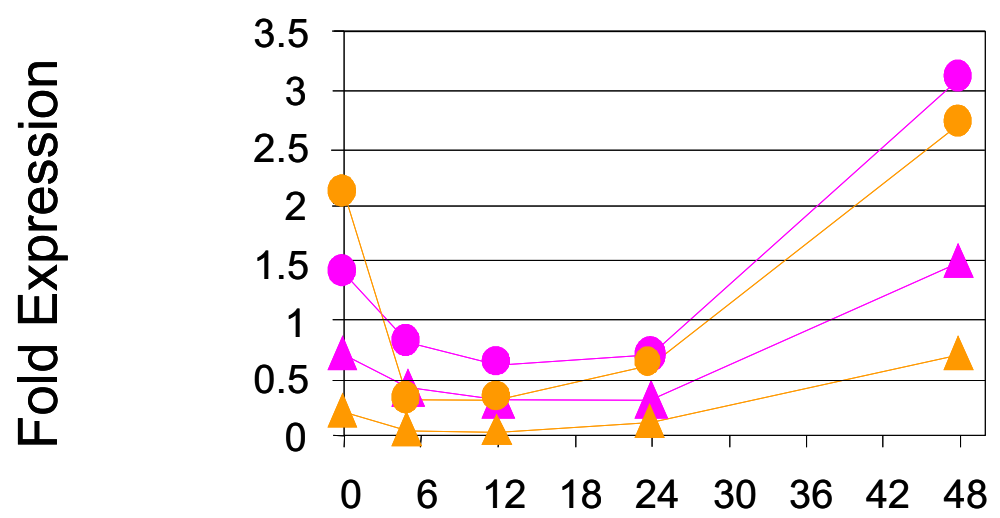

\author{
- 648 qRT-PCR \\ - $648 \mathrm{MA}$ \\ $\triangle \quad 1786$ qRT-PCR \\ - $1786 \mathrm{MA}$
}
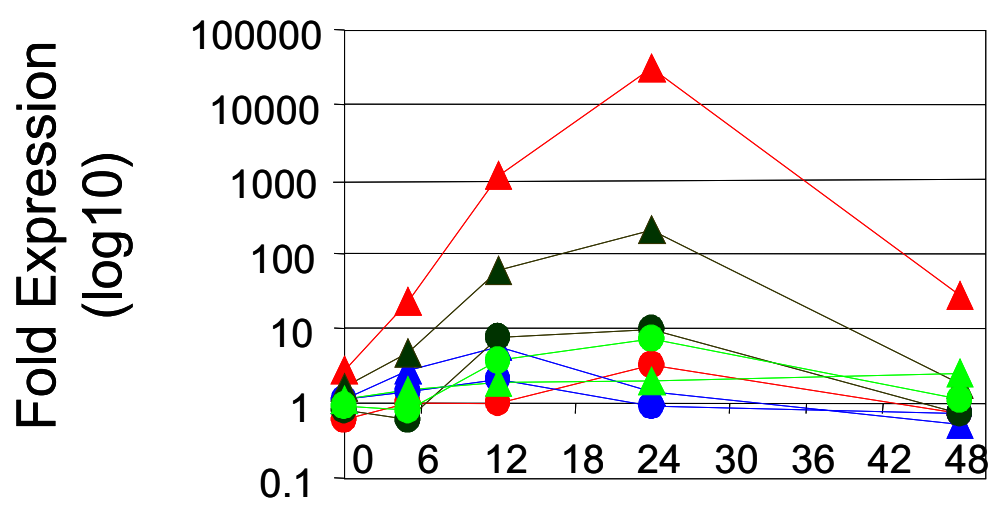
- 996 qRT-PCR
996 MA
1158 qRT-PCR
1158 MA
1949 qRT-PCR
1949 MA
679 (cl27) qRT-PCR
679 (cl27) MA

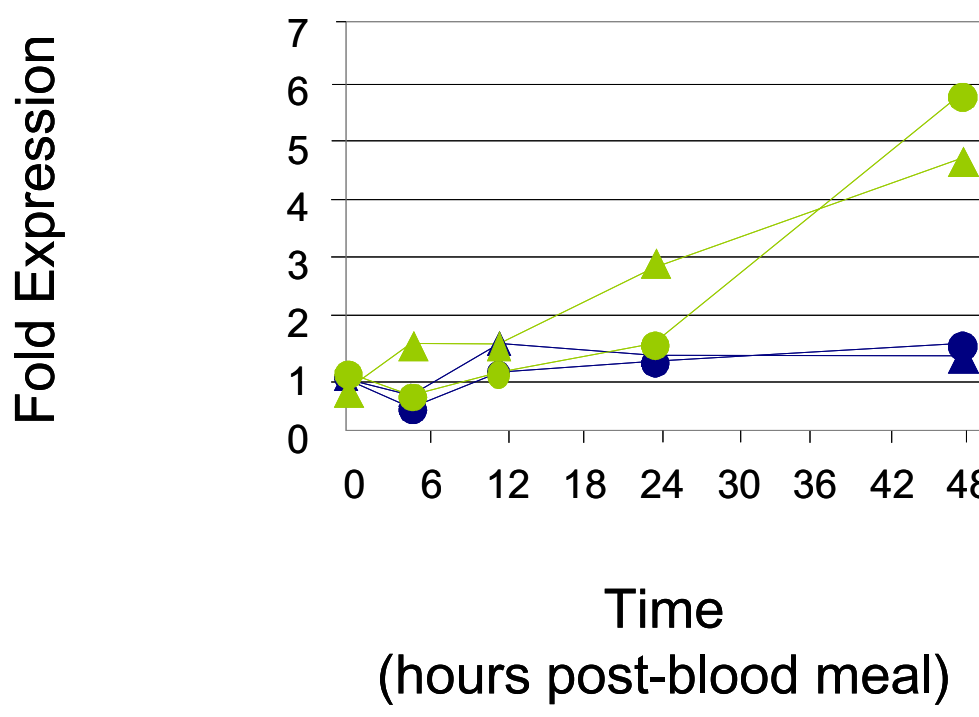

\title{
- 12 qRT-PCR \\ $12 \mathrm{MA}$ \\ 1357 qRT-PCR \\ $1357 \mathrm{MA}$
}

\section{Figure 4}

Comparison of microarray and qRT-PCR gene expression profiles for selected genes. X-Y plots were generated from the ratio of transcript levels in the blood-fed adult female mosquitoes to the transcript levels in the sugar-fed adult female mosquitoes for eight selected genes at five time points including 0, 5, 12, 24 and 48 hours post blood meal (PBM). Genes were randomly selected from the three sets and included ASs 648 and 1786 from the Early Genes (A), ASs 996, II 58 , 1949 , and 679 from the Middle Genes (B), and ASs 12 and 1357 from the Late Genes (C). Triangles indicate fold expression data generated by $q R T$ PCR analysis; circles indicate fold expression data generated by microarray analysis. A horizontal line connecting either the diamonds or circles illustrates each gene expression profile. For each gene, the expression profiles created by qRT-PCR and microarray analysis are indicated using the same color. 
hours, and then declines to baseline levels by 48 hours post blood ingestion [4-6]. In contrast to the Middle genes, most Late gene transcripts exhibited baseline, steady state levels until 12 hours PBM after which they were induced at least twofold and continued to exhibit increased transcript levels at 48 hours PBM. This increase in transcript levels mirrored the increase in $\mathrm{JH}$ titer observed by 48 hours post blood meal ingestion [50]. These results suggest that Middle genes products may be ecdysone-responsive whereas Late genes products may be $\mathrm{JH}$-responsive.

Based on their finding that the Drosophila minidiscs gene product showed a primary response to JH, Dubrovsky et al. [51] have suggested that JH may transcriptionally regulate genes encoding maternally inherited products. Our Late gene, AS 806, shares sequence similarity with minidiscs. Additionally, the majority of mosquito gene products showing sequence similarity to maternally active Drosophila genes are categorized as Late genes. Whether transcription of Early genes is directly influenced by levels of JH or 20-E, cannot be determined easily because neither hormone is present at high levels during the first few hours following blood meal ingestion. Regardless of expression pattern, the gene products in each set reflect a diverse array of processes occurring in the female mosquito within 48 hours following initiation of blood feeding. The major processes initiated in response to blood feeding including digestion, peritrophic matrix formation, oogenesis and vitellogenesis, are discussed below with emphasis on the likely roles of particular gene products.

\section{Digestion}

Digestion of the two different food sources, nectar sugars and blood, requires changes in the types of enzymes present within the digestive tract of the mosquito. The numbers of genes associated with sugar and protein metabolism within each set of genes may reflect the switch from sugar to protein metabolism. For instance, there are increases in transcript abundance of genes involved in carbohydrate metabolism and oxidative phosphorylation in the Early genes. However, both Early and Middle gene categories are enriched in genes involved in protein digestion. This result stems from the involvement of certain gene products in blood meal digestion that initiate a signaling cascade resulting in the up-regulation of other related proteolytic enzymes. The Middle genes contain the majority of gene products involved in amino acid metabolism, a process that follows protein digestion, whereas by 48 hours PBM, the time at which the majority of Late genes are induced, there is a generalized decrease in digestive enzyme transcripts.
Considering that blood contains large quantities of protein, the mosquito requires a variety of proteolytic enzymes to digest the recently acquired meal. In the present study, 11 genes were identified whose products are most likely required for protein digestion. These include 5 previously characterized digestive enzyme genes, two trypsins, a chymotrypsin, a serine protease and a carboxypeptidase. The majority of these digestive enzyme genes were transcribed at levels greater than twofold induction after 6 hours PBM. The An. gambiae Trypsins 1 and 2 are both induced by a blood meal and exhibit similar expression profiles although Trypsin 1 is expressed at higher levels. Muller and coworkers, using an RT-PCR strategy, showed that Trypsin 2 mRNA is present at $8,12,24$ and 28 hours post blood meal $[18,52]$. In our study, the Trypsin 2 gene (AS 569) also exhibited increased transcript abundance at 12 hours PBM with maximal expression occurring at 24 hours PBM, but these levels decreased by 48 hours. In contrast to Trypsins 1 and 2, Trypsins 3, 4, and 7 are constitutively expressed in nonbloodfed females. By 4 hours following a blood meal, levels of Trypsin 4 become undetectable by Northern and RTPCR analysis and do not reappear until 20 hours PBM [18] and unlike Trypsins 1 and 2, Trypsin 4 reaches maximal expression by 48 hours, near the end of the gonotrophic cycle. Our study identified two clones corresponding to Trypsin 4 (AS 568) but the two cDNAs exhibited different expression patterns. One (Accession no. CD747033) reached maximal transcript abundance at 48 hours PBM, the expected expression pattern. However, the other cDNA (Accession no. CD747029) was expressed at high levels prior to 6 hours PBM and also reached at least twofold increased levels by 48 hours PBM. These cDNAs may not have clustered together for technical reasons intrinsic to Seqman II, or they may correspond to alternatively spliced variants of the same gene. The sequence alignment showed $97 \%$ nucleotide sequence identity between the two ESTs over the region common to both. However, the CD747033 EST is only 253 bp in length and it is possible that the full-length cDNA represents an alternatively spliced transcript. In addition to Trypsins 2 and 4, we identified a trypsin-like serine protease (AS 648) which shared the greatest amino acid similarity with Trypsin 4 . However, this serine protease exhibited highest nucleotide identity to a different region of chromosome $3 \mathrm{R}$ than that containing all previously identified digestive trypsins. This gene product was induced greater than twofold within 6 hours PBM and was repressed during the height of digestion. Unlike Trypsins $3-7$, it was not expressed at higher levels at 48 hours PBM. It is possible that this trypsin is not involved in digestion but in another proteolytic process that is down-regulated following a blood meal. 
Barillas-Mury et al. [53] demonstrated that the early trypsin activity is essential to the transcription and subsequent expression of the late trypsins in Ae. aegypti. An. gambiae Trypsins 3-7 may indirectly activate transcription and increase the expression of Trypsins 1 and 2, the major endoproteolytic enzymes required for blood meal digestion [18]. In both Ae. aegypti and An. gambiae, these early expressed digestive enzymes are presumed to act as signal transducers causing transcriptional up-regulation of the late expressed ones $[14,53]$. Thus the digestive process is regulated by an elaborate biphasic expression pattern of serine proteases. Additional evidence suggests that not only tryptic peptides but cleaved amino acids may serve as systemic signals regulating subsequent processes. In contrast to the trypsin by-products, cleaved amino acids may also function as negative regulators of food intake. AS 1158 shared weak sequence similarity with the Drosophila pumpless protein, a larval fat body-expressed enzyme involved in glycine catabolism. In the fruit fly, larvae expressing the pumpless mutation are unable to pump food from the pharynx to the esophagus [54]. These mutant animals do not feed, neither do they upregulate genes normally involved in responses to starvation. Because feeding amino acids to wild type larvae phenocopied effects of the pumpless mutation, Zinke et al. [54] proposed that amino acids released from the fat body normally act as signals for cessation of feeding.

In addition to the trypsins, three chymotrypsin genes have been characterized in An. gambiae $[19,20]$. The expression of two of these digestive enzymes, AnChym 1 and 2, has been localized to the mosquito midgut by analysis of Northern blots [19]. RT-PCR showed that both chymotrypsin genes are expressed at 12 hours PBM and are abundant until 48 hours PBM, unlike transcripts of Trypsins 1 and 2 which have decreased dramatically by this time [19]. The cDNA representing chymotrypsin 2, AS 99, was categorized as a Late gene since maximal transcript levels were achieved after 24 hours PBM. In contrast, the other characterized chymotrypsin, AgChyL, exhibits changes in transcript abundance which is more similar to those of Trypsins 3-7. mRNA is present in non-blood fed females, detectable until 8 hours post blood meal after which mRNA can no longer be measured until 48 hours PBM [20]. The cDNA corresponding to this chymotrypsin-like serine protease, AS 994, was induced more than twofold prior to the peak of digestion and clustered with the Early Genes. In addition to the aforementioned chymotrypsins, our study identified a previously uncharacterized chymotrypsin (AS 2243) also located on chromosome 2L but in a different region from both AnChym1 and AnChym2. Exhibiting an expression pattern different from both AnChym 2 and AgChyL, this gene product was characterized as a Middle Gene with maximal transcript levels achieved between 12 and 24 hours PBM and a return to baseline by 48 hours PBM, similar to the expression patterns of Trypsins 1 and 2.

Edwards et al. [21] investigated expression levels of An. gambiae carboxypeptidase A following blood meal ingestion. Northern blot analysis indicated that levels of Carboxypeptidase A mRNA rose rapidly to a ten-fold increase within 3-4 hours following a blood meal, then dropped to the pre-induction state by 24 hours PBM. We identified a carboxypeptidase gene located on chromosome 2L (AS 1742) that is transcribed in a manner similar to that of carboxypeptidase A. However another cDNA representing a carboxypeptidase (AS 44) exhibited a radically different expression pattern. Transcripts were present at low levels 1-5 hours PBM but increased more than twofold between 12 and 24 hours PBM, a pattern that resembled the enzymatic activity in An. stephensi observed by Jahan et al. [13], namely a rapid increase until 12 hours PBM, with a peak at 24 hours, followed by a steady decline over the next day.

In contrast to the An. gambiae carboxypeptidase A, the levels of aminopeptidase peaked around 30 hours in An. stephensi [12]. Additionally, Lemos et al. [14] recorded peak aminopeptidase activity at 24 hours PBM in An. gambiae. We identified two aminopeptidases with at least twofold increased expression during the 48 hours PBM. The first aminopeptidase, AS 340, reached peak transcript levels at 24 hours PBM, showing a similar expression pattern to the enzyme activity levels reported by Billingsley and Hecker [12] and Lemos et al. [14]. In contrast, the other aminopeptidase, AS 430, showed amino acid similarity to the Ae. aegypti aminopeptidase $\mathrm{N}$. This aminopeptidase was classified as a Late gene, due to increased transcript levels at 24 hours PBM but maximal levels were not achieved until 48 hours PBM. Jahan et al. [13] documented two different kinetic profiles of aminopeptidase enzymes in An. stephensi depending on whether the enzyme was soluble or membrane-associated. The soluble aminopeptidase exhibited a kinetic profile similar to AS 340 and to that presented by Billingsley and Hecker [12] with peak activity at 24 hours PBM.

Geering [55] had suggested that phospholipase activity plays a role in blood digestion in Ae. aegypti although no conclusive evidence was demonstrated. However, Geering and Freyvogel [56] demonstrated that lipolytic activity increased 15 hours after blood feeding. Of the three gene products that are characterized as being involved in Fatty Acid/Lipid Metabolism and Transport, two, ASs 1177 and 997, encoding an acetate-CoA ligase and a fatty acid binding molecule, respectively, are expressed at more than twofold greater abundance at 24 hours PBM. These gene products may be involved in fatty acid degradation of 
blood meal components and the transport of these lipids to the oocytes.

The erythrocyte membrane contains a number of glycoproteins. It is therefore possible that enzymes normally associated with carbohydrate metabolism of nectar meals could also be involved in blood digestion. Almost all of the Simple/Complex Carbohydrate Metabolism and Transport genes identified in our study as being at least twofold upregulated were categorized as Early genes. Within the first 6 hours PBM, their transcripts are present at higher levels than in sugar-fed females and thereafter, they decrease steadily until 12 and 24 hours PBM. This expression profile does not exclude these genes from having a role in RBC glycoprotein metabolism. Several glycosidases are present within the midgut of An. stephensi, either associated with the lumen or with epithelial lysosomes [12]. The enzymatic activity of $\alpha$-glucosidase, the major midgut glycosidase in An. stephensi, increased from 6 hours PBM to maximal levels by 24 hours and decreased to basal levels by 36 hours PBM in the anterior midgut. The transcript abundance of the $\alpha$-glucosidase, AS1786, characterized in this study followed a different pattern than the enzymatic activity of An. stephensi $\alpha$-glucosidase. It showed greatest amino acid sequence similarity to Drosophila melanogaster gene product CG8690 $\alpha$-glucosidase and was categorized as an Early Gene with minimal transcript levels occurring at and after 24 hours PBM.

\section{Peritrophic matrix formation}

Shen and Jacobs-Lorena [34] characterized the An. gambiae peritrophic matrix protein Peritrophin 1 (Ag-Aper1) by analysis of Northern blots, and demonstrated that transcripts were present 6 hours PBM, increased by 12 hours, and remained elevated between 24-48 hours PBM. The present study identified several genes encoding proteins with a chitin-binding domain (InterPro ID IPR002557: Chitin binding Peritrophin-A) similar to the one found in Peritrophin 1. The Early gene AS 928 contains the Peritrophin-A chitin binding domain and maps to chromosome 3L in silico, corresponding to agCP10685. Another Early gene, AS 13, shows high identity to Peritrophin 1. A Middle gene, AS 516, is expressed by 6 hours PBM but does not reach maximal levels until 24 hours PBM. This gene product maps in silico to chromosome $2 \mathrm{~L}$, exhibits a similar transcript profile, and also shares $98 \%$ amino acid identity with Peritrophin 1. It is not clear why two sets of ESTs, both identified as Peritrophin 1, should exhibit different transcription patterns unless they are derived from differentially regulated genes. Another Middle gene, AS 1164, contains the Peritrophin-A chitin binding domain in addition to a prenyl-group binding site (InterPro ID IPR001230: CAAX box). This Middle gene may not be involved in peritrophic matrix formation but in some other process coinciding with protein digestion.
Two other cDNAs, Accessions CD746211 and CD746202, both in AS 13, could also be localized to chromosome $2 \mathrm{~L}$. However, their ESTs exhibited greatest nucleotide identity to the gene predicted as ENSANGG00000020776 located $4 \mathrm{~kb} 3$ ' to Ag-Aper1. These two cDNAs clustered as Early and Late genes respectively, and may represent alternatively spliced gene products.

As early as an hour after the adult female has taken a blood meal, secretory vesicles previously present in the apical brush border of midgut epithelial cells are no longer detectable [Staubli et al., 1966 as cited in [30]]. These apical granules presumably contain precursors of the peritrophic matrix. The Middle and Late peritrophin gene products may be packaged into vesicles in preparation for a subsequent blood meal. In contrast, the Early peritrophin genes may be transcribed in response to blood meal acquisition and their products used immediately in the formation of the peritrophic matrix.

\section{Ovarian cycle and oogenesis}

The extensive literature on genes involved in Drosophila ovarian development and early embryogenesis opens windows into interpreting our An. gambiae microarray results and understanding mosquito egg development. The majority of An. gambiae genes upregulated at least twofold following a blood meal appear to function in egg production. The only gene possibly involved in oogenesis during the early phases of the ovarian cycle is the Early gene AS 670. It shares sequence similarity with peter pan, a Drosophila gene product required during oogenesis. Oocytes in peter pan mutants often have an incorrect number of associated nurse cells, suggesting that the peter pan protein influences the separation of cells within the germaria [57]. The identification of other genes involved in the early stages of mosquito oogenesis may be facilitated by the construction of cDNA libraries from the abdomens or ovaries of recently blood fed female mosquitoes.

Several differentially expressed gene products found in the present study may be involved in the formation of ring canals, structures necessary for the delivery of maternal factors to oocytes. In particular, bulk transfer of cytoplasmic content from nurse cells to oocytes depends on actin structures [40]. A Middle gene product, AS 679, shares sequence similarity to the Drosophila gene CG13388 encoding the protein kinase anchor protein 200, Akap200. Akap200 protein localizes to ring canals during oogenesis, regulates protein kinase $\mathrm{C}$ activity, and controls their morphology [58]. Late gene product AS 1317 shows sequence similarity to the Drosophila pendulin gene product, encoded by CG4799. This gene product is also required for assembly of fully functional ring canals. pendulin encodes an importin- $\alpha 2$, a protein necessary for 
the localization of the kelch gene product, CG7210. kelch encodes an actin organizer without which the ring canals become occluded and nurse cell-oocyte cytoplasmic transport is inhibited $[59,60]$. Though we found an apparent pendulin gene, we did not find kelch. A Late gene product, AS 578, is the homolog of $C d c 42$, which encodes a small monomeric RHO GTPase involved in signal transduction. Rohatgi et al. [61] suggested that $C d c 42$ protein most likely links signal transduction to the actin cytoskeleton in Xenopus. In Drosophila ovaries, mutations in $C d c 42$ caused nurse cells to deflate and coalesce, and inhibited transfer of nurse cell cytoplasm to oocytes in late stage egg chambers [62].

Drosophila nurse cells transcribe the bicoid anterior determinant gene and the resulting mRNA is transported to the anterior region of developing oocytes via polarized microtubules [63]. bicoid does not appear to be an anterior determinant in other insects, but other genes important for its localization are conserved. The Early gene AS 2047 shares similarity with the Drosophila cornichon gene, CG5855. In Drosophila, cornichon is required for formation of a functional microtubular cytoskeletal scaffold used to transport bicoid mRNA and the posterior group oskar gene product to their proper location within the embryo [64]. The Late gene product, AS 1044 exhibits greatest sequence similarity to $D$. virilis exuperantia, a gene whose product is also required for proper bicoid mRNA localization D. melanogaster [65,66]. The Late gene AS 2222 is putatively identified as the An. gambiae homolog of Drosophila Notch. In Drosophila, Notch signaling regulates a large number of ovarian events beginning with cyst development in the germarium and extending through oogenesis [67]. The mechanisms by which Notch signaling activates transcription of its target genes are reviewed by Barolo and Posakony [68]. Since we identified Notch as a Late gene, its activities may be more restricted in An. gambiae, and/or reflect fundamental differences in ovarian biology. AS 1391, a Late gene product, shares sequence similarity with Drosophila Rab-protein 11. This Drosophila small monomeric RAB GTPase is also involved in the polarization of the microtubules for the organization of the posterior pole and for oskar localization there [69].

To regulate the progress of oogenesis and embryogenesis, stored maternal mRNAs are translationally repressed during early oocyte development. The Middle gene product AS 2031 shares sequence similarity with the Drosophila gene product Bicaudal $C$, a RNA binding protein that may play a role in translational silencing of maternal mRNAs in addition to its role in eggshell patterning [70]. Mutations in Bicaudal $C$ result in premature translation of oskar mRNA before it has reached the posterior region of the oocyte [71]. The Middle gene product AS 1490 is the putative homolog for the Drosophila gene product vasa
(CG3506), an ATP dependent helicase involved in pole plasm assembly that may also be involved in translational modification of maternal mRNAs [72]. The Late gene AS 453 shares sequence similarity with the Drosophila cup protein (CG11181). cup protein interacts with nanos, the posterior determinant, and a translational regulator of the gap gene hunchback mRNA during oogenesis, although the exact function of the cup protein still remains unknown [73]. A DEAD box protein encoded by vasa also influences oocyte differentiation and the development of the Drosophila embryo body plan via translation of oskar, nanos, and gurken during oogenesis [74-77]. In amphibians, several mRNA binding proteins have been identified that are only present in oocytes and not post cleavage embryos $[78,79]$. One An. gambiae Middle gene product, AS 2449, shared sequence similarity with the Xenopus laevis poly(A)-specific ribonuclease and also has mRNA binding motifs, thus it may also repress translation of mRNAs in embryos.

Maternal nurse cells not only provide the biosynthetic machinery and mRNA needed for oocyte axis determination, but also many transcripts and proteins required for zygotic development through the cellular blastoderm stage. The Middle gene product AS 1032 shares sequence similarity with nop5, encoding a maternally derived product of the Drosophila CG10206 gene, a component of the small nucleolar ribonucleoprotein (snoRNP) complex involved in rRNA processing [80]. The Late gene product AS 806, referred to above in the context of its possible regulation by $\mathrm{JH}$, shares sequence similarity with the Drosophila minidiscs gene product, an amino acid transporter. In Drosophila ovarian nurse cells, JH induces the expression of minidisks and its transcripts are most likely transferred to the oocyte during nurse cell cytoplasmic streaming [51].

Similar to the oocyte, the eggshell undergoes dorsal-ventral patterning. Crucial to this process is the correct placement of the oocyte relative to the maternal somatic follicle cells. In Drosophila, the localization of the oocyte depends on cadherin-associated adhesion [81]. The Late gene product AS 1890 is the homolog of $\alpha$-catenin, the CG17947 gene product. A cytoskeletal anchor protein, $\alpha$ catenin is required for positioning of the oocyte relative to the posterior follicle cells during germ cell rearrangement in Drosophila [81]. The RAS 1 signaling cascade is an important means of cell communication during embryo and eggshell patterning $[41,42]$. The Middle gene product AS 657 is weakly similar to the Drosophila Star protein, a RAS 1 enhancer involved in the EGF receptor signaling pathway, either upstream or in parallel to EGFR, during formation of the embryonic ventral midline. Star encodes a single pass transmembrane protein that may be involved in the processing of gurken protein. The DNA damage 
checkpoint 14-3-3epsilon protein also participates in RAS 1 signaling, normally functioning downstream or in parallel to RAF, but upstream of transcription factors. The Middle gene AS 106 shares sequence similarity with Drosophila 14-3-3epsilon. The 14-3-3epsilon protein is also capable of binding to a large number of other proteins in a phosphorylation-dependent manner. One of its functions may be to alter the cell cycle by binding Cyclin B and appears to have homologs in most if not all eukaryotes [82,83]. The An. gambiae Cyclin B homolog, AS 1357, grouped as a Late gene.

Mutation screens in Drosophila have led to the identification of a number of other gene products that may be involved in RAS 1 signaling. TppII (tripeptidyl-peptidase II), and smt3 (SUMO) were discovered in a search for lethal mutations that could enhance a weak RAS 1 eggshell phenotype [84]. The Middle gene product AS 1268 shares sequence similarity with Drosophila tripeptidyl-peptidase II, the CG3991 gene, encoding a serine protease that degrades neuropeptide signals [85]. The Late gene product AS 922 is the homolog of Drosophila smt3, CG4494, whose product is ubiquitin-like protein that may tag proteins for nuclear localization or retention in the cytoplasm [86,87]. smt3 protein may modulate activity of transcription factors in the follicle cells downstream of EGFR activation. However, we feel that $s m t 3$ is likely to be a minor player in RAS 1 signaling in the events following blood ingestion in the mosquito, because its mRNA reaches maximal expression after 12-24 hours PBM, unlike the other gene products we identified as potentially influencing RAS 1 signaling.

smt3 protein may also play a role in Toll signaling. This signal transduction pathway is known to be necessary for dorsal/ventral patterning of the Drosophila embryo. smt3 protein binds the NFאB homolog dorsal protein and targets this Rel transcription factor for migration to the nucleus [88,89]. Bhaskar et al. [88] demonstrated that smt3 conjugation to the dorsal protein enhanced its transcriptional activity. $s m t 3$ protein may play other roles in the cell by altering the interactions of septins, cytoskeletal proteins involved in cytokinesis [90,91]. In Drosophila, septins have been found in the cytoplasm of nurse cells and at the baso-lateral surfaces of follicle cells [92]. These results suggest even more pleiotrophc roles for the smt3 gene product in oogenesis. We also found that the Late gene AS 2034, a homolog of Drosophila Aos1, the CG12276 gene, the smt3 (SUMO) activating enzyme, was also expressed at least twofold more abundantly during the height of $s m t 3$ expression. This result reinforces the importance of smt3 in the events occurring between 2448 hours PBM.
In addition to genes regulating the polarity of the embryo and eggshell, genes involved in cellular growth and differentiation were differentially expressed during the 48 hours PBM ingestion. AS 337 and 495 shared sequence similarity with the Ae. aegypti ornithine decarboxylase antizyme, a protein that modulates polyamine synthesis. The homologous Drosophila ornithine decarboxylase antizyme gene, formerly known as gut feeling, has been shown to be important in developing oocytes. It is one target of Sex lethal which encodes an RNA binding protein that regulates mRNA splicing and the mitotic events in early germ cells via regulating Cyclin B [93]. The Late gene product AS 2073 shares sequence similarity with the Drosophila polo CG12306 gene product, a protein kinase required for cytokinesis and another regulator of Cyclin B [94]. The Early gene AS 1972 shows identity with the Drosophila black pearl CG5268 gene product. This protein contains DnaJ domains implying that it is necessary for cellular growth [95]. Northern blot analysis of black pearl RNA from various developmental stages showed two transcripts with greatest expression in Drosophila embryos 0-6 hours old [95], the stages in which DNA replication recurs most rapidly. The Late gene AS 2268 shares sequence similarity with the Drosophila Imaginal disc growth factor4 (Idgf4), a mitogen with a non-functional chitinase domain. Transcripts of $I d g f 4$ are detected in Drosophila nurse cells, oocytes, and in the yolk cytoplasm of early embryos [96]. The Middle gene product AS 2273 shares sequence similarity with Drosophila $\beta$ Integrin. An. gambiae $\beta$ Integrin may interact with the Middle gene AS 985 product to promote somatic cell adhesion and cell migration during oogenesis and embryogenesis. This is due to the similarity of the AS 985 gene to Drosophila Receptor of activated protein kinase $C$, RACK1. RACK1 can bind a number of different signaling and cell adhesion molecules including the activated form of protein kinase C (PKC), Src family kinases, and $\beta$ Integrins [97-99]. Cox et al. [100] demonstrated that, in a mammalian system, RACK1 organizes focal adhesions and directional cell migration via its Src-binding site. Mahairaki et al. [101] found that the An. gambiae $\beta$ Integrin gene was expressed at highest levels 48 hours PBM, whereas we found that the $\beta$ integrin homolog reached at least twofold increased expression by 24 hours PBM.

A number of genes have been implicated in the development of the egg shell structures. Our screen does not appear to have identified any homologs of the several endochorionic structural proteins characterized in $\mathrm{Ae}$. aegypti [102,103]. This was unexpected because Northern blot analysis had indicated that transcription of the vitelline membrane proteins 15a-1, 15a-2, 15a-3 was induced rapidly between 10 and 24 hours PBM, reached maximal levels between 30 and 40 hours PBM, and decreased to baseline levels between 50 and 60 hours PBM [102,103]. 
Our study also did not identify a Dopa decarboxylase (Ddc) gene, Ddc is an enzyme involved in the tyrosine metabolic pathway necessary for eventual chorion melanization in Ae. aegypti, and other melanization events. The gene is upregulated in response to blood meal with transcripts initially detectable by 12 hours PBM, and maximal levels achieved between 24 and 48 hours PBM [104]. However, we did identify a gene encoding another enzyme involved in tyrosine metabolism. AS 1340, a Middle gene product, shared sequence similarity with the Ae. aegypti Dopachrome conversion enzyme [105]. This enzyme is required for processing of dopachrome to melanin. It is interesting that its mRNA is constitutively expressed in $A e$. aegypti females, but becomes upregulated when they are infected with Dirofilaria [105]. Since insect melanins can be produced via any of three intermediates, Dopa, Dopamine, or Dopachrome, it may be that An. gambiae differs from Ae. aegypti in the substrate metabolized to produce chorionic melanin.

Several Middle and Late genes encoding antioxidants were upregulated at least twofold 12-48 hours PBM. The Middle gene, AS 2033, a glutathione S-transferase D3, and the three Late genes, ASs 1684, 35, and 2156, encoding glutathione S-transferase 1-6 class theta, and homologs of Drosophila thioredoxin and Ae. aegypti 2-Cys thioredoxin peroxidase, may have roles in regulating reactive oxygen species that can be produced from the highly reactive quinones which are normally cross-linked into melanin immediately after they are formed.

\section{Ovarian cycle and vitellogenesis}

Paramount to the development of the embryo is the massive accumulation of vitellogenin by the oocyte. In An. gambiae there is a small, polymorphic tandem array of vitellogenin genes and a single dispersed vitellogenin gene, all located on Chromosome 2R in division 18B (P. Romans and M. Sharakhova, unpublished observations). Vitellogenin mRNA becomes detectable by Northern blot analysis by 8 hrs PBM, though it is detectable earlier by RT-PCR, increases dramatically by 12 hours, reaches maximal levels by 24 hours, and declines to undetectable levels by 48 hours PBM [47]. Our microarray study identified three cDNAs, all Middle gene products and greater than twofold induced, as vitellogenin gene homologs. Two of the ESTs were not conjoined during EST assembly because they represented non-overlapping $5^{\prime}$ and $3^{\prime}$ ends of the $\mathrm{Vg} 1$ gene. The third EST included the more closely resembled the sequence of the dispersed vitellogenin gene (P. Romans and A. Dana, unpublished). As expected, all three vitellogenin clones exhibited expression profiles similar to the overall pattern previously described [47].

Following synthesis in the fat body, vitellogenins are released into the hemolymph. Eventually, they diffuse through channels between the cells of the follicular epithelium and are accumulated by the oocyte by receptormediated endocytosis in clathrin-coated pits [8]. The increased number of gene products involved in receptormediated endocytosis before and after the height of vitellogenin gene transcription, 12-24 hours PBM in this study, may reflect a preparation for the increase in receptor-mediated endocytosis when the oocytes are accumulating vitellogenins and other yolk constituents during the trophic phase of the ovarian cycle. These genes included an Early gene, AS 1974, similar to the Drosophila Adaptin subunit, $A P-1 \sigma$, CG5864, and the Late gene, AS 2086, homolog of another Drosophila clathrin-associated protein, AP-50, CG7057.

When vitellogenesis has ceased, the biosynthetic machinery in the fat body is degraded in lysosomes [46]. In Ae. aegypti, the lysosomal cathepsin D-like aspartic protease (AeLAP) exhibited a similar transcription profile to vitellogenin [106]. Cho et al. [107] also identified a Cathepsin B-like thiol protease, vitellogenic Cathepsin B or VCB, which is secreted from the fat body with a peak at 24 hours PBM and incorporated into oocytes. It appears to be involved in the degradation of vitellin in embryos. The Middle gene AS 996, a Cathepsin B, shares identity with this Ae. aegypti protein, exhibits the same expression profile, and may be its homolog. At approximately 30 hours PBM, 6 hours after peak production of vitellogenin, the activity of four other lysosomal enzymes, arylsulfatase A, acid phosphatase-1, $\beta$-galactosidase, and Cathepsin $\mathrm{D}$, has dramatically increased to reach maximal levels by 3642 hours PBM $[108,109]$. The two Late gene products, ASs 1254 and 2231, were identified putatively as the lysosomal enzymes, acid phosphatase- 1 and Cathepsin F, respectively. These genes also may be involved in the termination phase of vitellogenesis. Cathepsin F is necessary for oocyte growth in a teleost fish and has been suggested to be associated with yolk protein processing [110]. It will be a very interesting example of gene co-evolution, should processing of vitellogenins, proteins conserved between egg-laying vertebrates and non-Brachyceran insects, actually be accomplished by similarly conserved cathepsins.

\section{Conclusions}

Holt et al. [49] performed the first genomic-scale study of hematophagy in An. gambiae by identifying 168 ESTs that differed in statistical abundance between CDNA libraries made from adult female mosquitoes fed on sugar and 24 hours PBM. Ribeiro [111] extended this study by describing an additional 267 such genes. We have expanded on these studies by identifying additional 359 ESTs and by examining virtually a complete first gonotrophic cycle experimentally. In addition, we found 18 ESTs present in our microarray and Ribeiro's [111] studies. All but one (AS 205) showed the same expression patterns at 24 hours 
Table 8: List of genes differentially expressed* in female A. gambiae at 24 hours post-blood meal in both microarray and in silico (Ribeiro, 2003) gene expression studies.

\begin{tabular}{|c|c|c|c|c|c|}
\hline AS ID & EnsembI ID & Microarray & in silico & Molecular Functions & Biological Processes \\
\hline 99 & $\operatorname{agCP} 3 \mid 23$ & $U_{p}$ & $U_{p}$ & enzyme & Protein Digestion \\
\hline 996 & agCPI4019 & $U_{p}$ & $U_{p}$ & enzyme & Egg Development \\
\hline 2222 & agCP8969 & Up & Up & unknown & Unknown \\
\hline 1949 & agCPI 2846 & Up & Up & unknown & Unknown \\
\hline 1317 & agCP8818 & $U_{p}$ & $U_{p}$ & transporter & Transport \\
\hline 516 & agCP3409 & $U_{p}$ & $U_{p}$ & binding & Structural \\
\hline 1044 & agCP3927 & $U_{p}$ & $U_{p}$ & unknown & Egg Development \\
\hline 995 & agCP570I & Up & Up & enzyme & Protein Digestion \\
\hline 230 & agCP25। 8 & $U_{p}$ & $U_{p}$ & nutrient reservoir & Egg Development \\
\hline 180 & agCPIIII & $U_{p}$ & $U_{p}$ & unknown & Unknown \\
\hline 2207 & agCPI5442 & $U_{p}$ & $U_{p}$ & transporter & Ion Transport \\
\hline 2256 & agCP273I & $U_{p}$ & $U_{p}$ & unknown & Unknown \\
\hline 2243 & $\operatorname{agCP} 3610$ & $U_{p}$ & $U_{p}$ & enzyme & Protein Digestion \\
\hline 205 & agCP5849** & Down & $U_{p}$ & unknown & Unknown \\
\hline 86 & agCP6049 & Down & Down & unknown & Unknown \\
\hline 553 & agCPI| 425 & Down & Down & transporter & Oxidative phosphorylation \\
\hline 2123 & agCPII4I6 & Down & Down & transporter & Transport \\
\hline 642 & agCP8।9| & Down & Down & structural molecule & Cuticle biosynthesis \\
\hline
\end{tabular}

*; These genes displayed at least 2-fold up- or down-regulation relative to the control.

**: AS 205 shows discrepancy between microarray and in silico expression data.

Up: up-regulation; Down: down-regulation.

PBM (Table 8). These highly synchronous expression profiles of those ESTs further validate that experimental microarray and in silico data can complement each other. However, our study is unique in that we have determined the temporal patterns of expression of the genes we identified. The observed similarities between the gene expression patterns and production of the two principal insect hormones suggest that gene transcription may be influenced by changes in JH titers as well as by 20-E levels, a phenomenon that has been well-studied in the context of Drosophila metamorphosis and in Ae. aegypti vitellogenesis. Future analysis may reveal genes co-regulated via the same promoters. Indeed, this now appears possible for organisms whose genomes have been sequenced [112114]. As new regulatory sequences are identified, the arsenal of transcriptional regulators to drive their tissue- and stage-specific gene expression will be increased. We expect that this increased promoter availability will supplement current vector-control strategies.

Great progress has been made in the annotation of the An. gambiae genome, culminating in the public announcement of the genome sequence in 2002 and its subsequent updates. Yet, although we have identified 413 differentially expressed gene products, we could not assign almost half of them to a biological process. Of the 200 "Unknowns," 43 unique transcripts shared no significant identity with sequences in the $\mathrm{Nr}$ and dbEST databases. The genes corresponding to these transcripts may be iden- tified following the second gene build of the An. gambiae genome. Functional studies using microarray analysis verified by qRT-PCR must confirm in silico predicted annotations and provide biological information about gene products. Many of the gene products identified in this study share sequence similarity with Drosophila proteins. Much of the information generated by studies of fruit fly cell biology and development may also apply to mosquitoes, although it will be more difficult to test in An. gambiae, since it is not easily manipulated genetically. This study underscores the importance of ongoing functional studies including tissue-specific expression profiling using microarray analysis and qRT-PCR. Understanding how the events following blood feeding are related to each other on a molecular level will provide a more comprehensive picture of this unique behavior and may also delineate new vector-control strategies.

\section{Methods}

\section{Microarray chip fabrication}

Three cDNA libraries were constructed from abdomens of adult female An. gambiae which had been sugar-fed (harvested 30 hours post-eclosion), rat blood-fed (harvested 30 hours PBM), and P. berghei-infected rat blood-fed (harvested 30 hours $\mathrm{PBM})$, all at $19^{\circ} \mathrm{C}$ (Dana, unpublished $\mathrm{PhD}$ thesis). Clones from all three libraries were subjected to PCR-based insert amplification using $\lambda$ TriplEx2 vector specific primers (3' LD Amplimer Primer 5'-ATACGACTCACTATAGGGCGAATTGGC-3'; 5' LD Amplimer Primer: 
5'-CTCGGGAAGCGCGCCATTGTGTTGG-3'). Amplification reactions contained $1.0 \mu \mathrm{L}$ eluted phage, $0.03 \mathrm{pmol}$ of each primer, $1 \times$ Taq Polymerase Buffer (Invitrogen), 3 $\mathrm{mM} \mathrm{MgCl}_{2}, 1 \mathrm{mM}$ of each dNTP, and 0.2 U Taq Polymerase (Invitrogen), in a total volume of $100 \mu \mathrm{L}$. Reactions were conducted in 96-well plates on a Perkin-Elmer 9700 Thermocycler using the following cycling conditions: initial denaturation at $95^{\circ} \mathrm{C}$ for $5 \mathrm{~min}$, followed by 35 cycles of denaturation at $94^{\circ} \mathrm{C}$ for $30 \mathrm{~s}$, annealing/elongation at $70^{\circ} \mathrm{C}$ for $2 \mathrm{~min}$, and a final elongation step at $68^{\circ} \mathrm{C}$ for 3 min. Samples of all PCR products were electrophoresed on $1 \%$ agarose, $1 \times$ TBE gels and visualized by ethidium bromide staining. PCR products were purified on a Beckman Biomek FX using Montage PCR 96 Cleanup kits (Millipore), eluted in $100 \mu \mathrm{L}$ of water, evaporated overnight and the pellets resuspended in $30 \mu \mathrm{L}$ of $3 \times$ SSC microarray spotting buffer. A total of 3060 resuspended cDNA inserts and 108 controls were spotted in triplicate on CMT-Gaps II slides (Corning, NY) using the Affymetrix Arrayer 417 at $19-20^{\circ} \mathrm{C}$ and relative humidity between $50-60 \%$. Slides were post-processed by baking at $80^{\circ} \mathrm{C}$ for three hours, incubation in $1 \%$ SDS for $2 \mathrm{~min}$, in $95^{\circ} \mathrm{C}$ purified water for a further $2 \mathrm{~min}$, and then plunged 20 times into $100 \%$ ethanol kept at $-20^{\circ} \mathrm{C}$ and air-dried via centrifugation at $500 \mathrm{RPM}$ for $5 \mathrm{~min}$.

\section{Microarray target preparation and hybridization}

Total RNA was extracted from blood-fed and sugar-fed whole adult female mosquitoes of the malaria susceptible 4Arr strain, 5-7 days post eclosion, using Trizol (Molecular Research Center, Inc) according to the manufacturer's directions. Mosquitoes were blood-fed on anesthetized white rats and maintained under conditions similar to those for sugar-fed mosquitoes, $25^{\circ} \mathrm{C}$ with $80 \%$ humidity and a 12-h light/dark cycle with available 20\% sucrose solution, until collection. Fully-engorged mosquitoes were identified visually and harvested at the following 10 time-points: 1) $5 \mathrm{~min}$ after initiation of blood feeding during the acquisition of the blood meal (DBM), 2) 30 min DBM, 3) 0 hr post-blood meal (PBM), immediately after they ceased feeding on the rat, 4) $1 \mathrm{hr}$ PBM, 5) $3 \mathrm{hr}$ PBM, 6) $5 \mathrm{hr}$ PBM, 7) $12 \mathrm{hr}$ PBM, 8) $16 \mathrm{hr}$ PBM, 9) $24 \mathrm{hr}$ PBM, and 10) $48 \mathrm{hr}$ PBM. For each blood-fed sample, total RNA was extracted from batches of approximately 10-15 females. Total RNA was also extracted from batches of 100 sugar-fed females for reference samples. RNA samples were then treated with $1.0 \mu \mathrm{L}$ DNase I (Life Science Technology) according to manufacturer's instructions. Following DNase I treatment, total RNA was re-extracted with Trizol. First strand cDNA synthesis and labeling with Cyanine 3 (Сy3) or Cyanine 5 (Cy5), were performed on 15 $\mu \mathrm{g}$ of total RNA from each sample using the Genisphere 3DNA Array 50 kit according to the manufacturer's protocol. Hybridizations were conducted following the two step protocol recommended by the manufacturer: 1)
cDNA hybridization to the amplified cDNA probes spotted on the slides, 2) hybridization of 3-DNA fluorescent dendrimers (Genisphere) to cDNAs via the capture sequences incorporated into them during first strand synthesis. All cDNA and fluorescent dye hybridizations were performed in a volume of $50 \mu \mathrm{L}$ using the formamidebased hybridization buffer provided by the manufacturer. The cDNA hybridizations were performed at $45^{\circ} \mathrm{C}$ overnight. The slides were then washed according to the 3DNA Array 50 kit protocol and air dried by centrifugation for 3 min at 800 RPM. The 3-DNA hybridizations were performed at $53^{\circ} \mathrm{C}$ for 2 hours as described above, except that $0.5 \mathrm{mM}$ DTT was added to the first two wash solutions to protect the fluorochromes from oxidation. Five replicate slides were generated for each of the ten time points for a total of 50 hybridized and labeled slides. These included two dye-swap experiments performed to eliminate dye fluorescence bias. Pilot experiments conducted with total RNA from the same sample labeled with both Cy3 and Cy5, self-self hybridization, indicated that there was no dye labeling bias following data normalization (data not shown).

\section{Microarray data acquisition and statistical analysis}

Following hybridization and washing, microarray slides were scanned successively at 532 and $635 \mathrm{~nm}$ using the Affymetrix 428 Array Scanner. Raw signal intensities were acquired using the adaptive circle algorithm and spot intensities quantified using the Jaguar 2.0 segmentation and data analysis software (Affymetrix, CA). Average signal intensities were normalized using the Loess curve for intensity dependent normalization followed by a per gene median normalization using the Genespring 5.1 software (Silicon Genetics, CA). Signal intensities were filtered such that only gene products exhibiting a raw signal intensity value greater than 300 pixels in one channel and greater than two-fold expression difference between the sugar-fed and blood-fed samples from at least one time point hybridized to the same array were utilized in further analysis. Gene expression level measurements falling outside one standard deviation from the mean signal intensity of each gene product calculated from the five replicates were excluded from further analysis. As an additional quality control, only genes whose PCR amplified products migrated as a single band in agarose gel electrophoresis and that generated high quality sequences for use in EST assembly were analyzed.

Gene products that were induced or repressed at least twofold during blood feeding were initially clustered hierarchically using the Genespring software to determine the user-defined number of centroids (clusters) to be used in $k$-means clustering (data not shown). From this preliminary analysis it was determined that three major clades existed and the genes were clustered using Genespring 
software using a $k$-means clustering algorithm with a centroid number of 3 and the Pearson Correlation distance metric. Finally, an independent analysis using principal components analysis (PCA) was conducted on the genes induced or repressed at least twofold, using the Genespring software.

\section{qRT-PCR}

Transcript levels of several selected genes were measured using SYBR dye technology (Applied Biosystems, CA) and quantitative real-time PCR (qRT-PCR) analysis in order to validate microarray data,. The Primer Express Software v. 1.5 (Applied Biosystems, CA) was used to design the following primers to nine genes: the two Early Genes agCP4871 (AS 648; Forward 5'-TGATTCGTGCCAGGGTGAT-3'; Reverse 5'-CACCACACCAACAAGGACATC-3') and CG8690 (AS 1786; Forward 5'-GCTGACTTTGAGCGGTTGG-3'; Reverse 5'-CACAAAGTCCATGATCACCTTCA3'), the four Middle Genes agCP8064 (AS 679; Forward 5'TGGCGAGGTCGATCAGCTA-3'; Reverse 5'-CATTATCGCCATCGTTGTGTTG-3'), agCP12846 (AS 1949; Forward 5'-TTTGTGGTTCGGTATCGATCTG-3'; Reverse 5'-CGAGCACTTTGGCGAACTTC-3'), CG7758 (AS 1158; Forward 5'-CACGGTTGGCATTTCGAAC-3'; Reverse 5'GCAGCTGTGCGAACACCA-3'), and agCP14019 (AS 996; Forward 5'-GTCGGGCGATTCCAATGA-3'; Reverse 5'TGTAACCGGGCTGGCAAA-3'), and the two Late Genes agCP14623 (AS 12; Forward 5'-CGGCAAATCGGTTCAGCT-3'; Reverse 5'-TGAATCGGTGCCTTGCG-3') and agCP2112 (AS 1357; Forward 5'-CCTGCATGAAGGTGGAATGA-3'; Reverse 5'-TTGCCAAGCTCTCCCAACAC3'), and the ribosomal protein S7 (RP S7) gene control (Forward 5'-CATTCTGCCCAAACCGATG-3'; Reverse 5'AACGCGGTCTCTTCTGCTTG-3'). RP S7 was used as an internal control since its expression is constitutive during blood-feeding [115-118]. All amplifications and fluorescence quantification were performed using an ABI 7700 Sequence Detection System and associated Sequence Detector Software v. 1.7 (Applied Biosystems, CA). Standard curves were generated using 10-fold serial dilutions of genomic DNA (ranging from 0.0116 to $116 \mathrm{ng}$ per reaction). These qPCR reactions were performed in duplicate in a total volume of $25 \mu \mathrm{L}$ containing $12.5 \mu \mathrm{L}$ of SYBR green PCR Master Mix, $300 \mathrm{nmol}$ of each primer, and nuclease free water (Gibco, UltraPURE) using the following conditions; $50^{\circ} \mathrm{C}$ for $2 \mathrm{~min}$, then denaturation at $95^{\circ} \mathrm{C}$ for $10 \mathrm{~min}$ followed by 45 cycles of denaturation at $95^{\circ} \mathrm{C}$ for $15 \mathrm{~s}$, annealing and extension at $60^{\circ} \mathrm{C}$ for $1 \mathrm{~min}$. qRT-PCR reactions for quantification of transcript levels were conducted using $50 \mathrm{ng}$ of first strand cDNA prepared from RNA samples isolated for the microarray analysis. The abundance of each transcript in an RNA sample was estimated from the corresponding gene's standard curve and normalized against RP S7 transcript abundance in the same RNA sample.

\section{Authors' contributions}

AND carried out the cDNA library construction, microarray fabrication, data analysis, and drafted the manuscript. YSH performed the microarray experiment, data analysis, and helped draft the manuscript. MKK performed the qRT-PCR experiments and MEH annotated the ESTs. BWH constructed the microarray genechips and carried out microarray data acquisition. NFL sequenced the cDNA library and JRH maintained and provided mosquito samples throughout the project. PR assisted AND and YSH to draft the manuscript and reviewed it. FHC (P.I.) initiated and supervised the project. All authors read and agreed on the final version of this manuscript.

\section{Additional material}

\section{Additional File 1}

Supplementary Table S1 in a Microsoft Excel format where gene annotations for all 413 at least twofold differentially expressed gene products are given.

Click here for file

[http://www.biomedcentral.com/content/supplementary/1471-

2164-6-5-S1.xls]

\section{Acknowledgements}

We are grateful to Dr. M. Ferdig of the University of Notre Dame for his constructive discussion throughout the work. We also acknowledge the technical support of Hannah Kim who performed cDNA selections for microarray fabrication. This project was supported by grants $\mathrm{UOI}$-Al48846 and ROI-Al44273 from NIH/NIAID to F.H.C. Additional support was provided by a grant to P.R. from the Natural Sciences and Engineering Research Council of Canada.

\section{References}

I. Beklemishev WN: Gonotrophic rhythm as a basic principle of the biology of Anopheles. Voprosy Fiziologii i Ekologii Malyariinogo Konara 1940, I:3-22.

2. Baker FC, Hagedorn HH, Schooley DA, Wheelock G: Mosquito juvenile hormone identification and bioassay activity. J Insect Physiol 1983, 29:465-470.

3. Brown MR, Graf R, Swiderek KM, Fendley D, Stracker TH, Champagne $D E$, Lea $A O$ : Identification of a steroidogenic neurohormone in female mosquitoes. J Biol Chem 1998, 273:3967-397I.

4. Lea AO, Brown MR: Neuropeptides of mosquitoes. In Molecular Insect Science Edited by: Law JH. New York, Plunum Press; 1990:181-188.

5. Hagedorn HH, O'Connor JD, Fuchs MS, Sage B, Schlaeger DA, Bohm MK: The ovary as a source of alpha-ecdysone in an adult mosquito. Proc Natl Acad Sci U S A 1975, 72:3255-3259.

6. Hanaoka $\mathrm{K}$, Hagedorn $\mathrm{HH}$ : Brain control of ecdysone secretion by the ovary in a mosquito. In Progress in Ecdysone Research Edited by: Hoffmann JA. , Elsevier/North Holland Biomedical Press; 1980:467-480.

7. Racioppi JV, Gemmill RM, Kogan PH, Calvo JM, Hagedorn HH: Expression and regulation of vitellogenin messenger RNA in the mosquito, Aedes aegypti. Insect Biochem Insect biochem 1986, 16:255-262.

8. Raikhel AS, Dhadialla TS: Accumulation of yolk proteins in insect oocytes. Annu Rev Entomol 1992, 37:217-25I.

9. Raikhel AS, Kokoza VA, Zhu J, Martin D, Wang SF, Li C, Sun G, Ahmed A, Dittmer N, Attardo G: Molecular biology of mosquito vitellogenesis: from basic studies to genetic engineering of 
antipathogen immunity. Insect Biochem Mol Biol 2002 32:1275-1286

10. Fisk FW: Studies on proteolytic digestion in adult Aedes aegypti mosquitoes. Annal Ent Soc Amer 1950, 43:555-57|.

II. Briegel $\mathrm{H}$ : Excretion of proteolytic enzymes by Aedes aegypti after a blood meal. J Insect Physiol 1975, 21:168I-1684.

12. Billingsley PF, Hecker $\mathrm{H}$ : Blood digestion in the mosquito, Anopheles stephensi Liston (Diptera: Culicidae): activity and distribution of trypsin, aminopeptidase, and alpha-glucosidase in the midgut. J Med Entomol I99|, 28:865-87|

13. Jahan N, Docherty PT, Billingsley PF, Hurd H: Blood digestion in the mosquito, Anopheles stephensi: the effects of Plasmodium yoelii nigeriensis on midgut enzyme activities. Parasitology 1999, I I 9:535-54I.

14. Lemos FJ, Cornel AJ, Jacobs-Lorena M: Trypsin and aminopeptidase gene expression is affected by age and food composition in Anopheles gambiae. Insect Biochem Mol Biol 1996, 26:65I-658.

15. Horler $\mathrm{E}$, Briegel $\mathrm{H}$ : Chymotrypsin inhibitors in mosquitoes: activity profile during development and after blood feeding. Arch Insect Biochem Physiol 1997, 36:3 I5-333.

16. Graf $R$, Briegel $H$ : The synthetic pathway of trypsin in the mosquito Aedes aegypti L. (Diptera: Culicidae) and in vitro stimulation in isolated midguts. Insect Biochemistry 1989, 19:129-137.

17. Felix CR, Betschart B, Billingsley PF, Freyvogel TA: Post-feeding induction of trypsin in the midgut of Aedes aegypti L. (Diptera: Culicidae) is separable into two cellular phases. Insect Biochemistry 1991, 21:197-203.

18. Muller HM, Catteruccia F, Vizioli J, della Torre A, Crisanti A: Constitutive and blood meal-induced trypsin genes in Anopheles gambiae. Exp Parasitol 1995, $81: 37$ I-385.

19. Vizioli J, Catteruccia F, della Torre A, Reckmann I, Muller HM: Blood digestion in the malaria mosquito Anopheles gambiae: molecular cloning and biochemical characterization of two inducible chymotrypsins. Eur J Biochem 200I, 268:4027-4035.

20. Shen Z, Edwards MJ, Jacobs-Lorena M: A gut-specific serine protease from the malaria vector Anopheles gambiae is downregulated after blood ingestion. Insect Mol Biol 2000, 9:223-229.

21. Edwards MJ, Lemos FJ, Donnelly-Doman M, Jacobs-Lorena M: Rapid induction by a blood meal of a carboxypeptidase gene in the gut of the mosquito Anopheles gambiae. Insect Biochem Mol Biol 1997, 27:1063-1072.

22. Billingsley PF: Blood digestion in the mosquito, Anopheles stephensi Liston (Diptera: Culicidae): partial characterization and post-feeding activity of midgut aminopeptidases. Arch Insect Biochem Physiol 1990, I 5: I 43-163.

23. Hori K, Hori Y, Kuramochi K: DEAE-cellulose chromatography of trypsin-like enzyme and aminopeptidase in the midgut of the adult hornfly, Haematobia irritans (L.) (Diptera:Muscidae) and the adult stable fly, Stomoxys calcitrans (L.) (Diptera: Muscidae). Appl entomol Zool 1983, I 8:432.

24. Cheeseman MT, Gooding RH: Proteolytic Enzymes from Tsetse Flies Glossina-Morsitans and Glossina-Palpalis Diptera Glossinidae. Insect Biochemistry 1985, I 5:677-680.

25. Ferreira C, Terra WR: Substrate specificity and binding loci for inhibitors in an aminopeptidase purified from the plasma membrane of midgut cells of an insect (Rhynchosciara americana) larva. Arch Biochem Biophys 1986, 244:478-485.

26. Geering K: Lipase and unspecific esterase activity in the fat body of Aedes aegypti L. Acta Trop 1975, 32:273-276.

27. Geering K, Oberlin UP: The esterase patterns in the ovaries and the embryonated eggs of Aedes aegypti L. Acta Trop 1975, 32:48-56.

28. Freyvogel TA, jaquet $C$ : The prerequisites for the formation of the peritrophic membrane in Culicidae females. Acta Trop 1965, 22: 148-I54

29. Tellam RL, Wijffels G, Willadsen P: Peritrophic matrix proteins. Insect Biochem Mol Biol 1999, 29:87-I0I.

30. Clements AN: The Biology of Mosquitoes. London, Chapman and Hall; 1992.

3I. Berner R, Rudin W, Hecker H: Peritrophic membranes and protease activity in the midgut of the malaria mosquito, Anopheles stephensi (Liston) (Insecta: Diptera) under normal and experimental conditions. J Ultrastruct Res 1983, 83:195-204.

32. Shahabuddin M, Toyoshima T, Aikawa M, Kaslow DC: Transmission-blocking activity of a chitinase inhibitor and activation of malarial parasite chitinase by mosquito protease. Proc Natl Acad Sci U S A 1993, 90:4266-4270.

33. Moskalyk LA, Oo MM, Jacobs-Lorena M: Peritrophic matrix proteins of Anopheles gambiae and Aedes aegypti. Insect Mol Biol 1996, 5:26I-268.

34. Shen Z, Jacobs-Lorena M: A type I peritrophic matrix protein from the malaria vector Anopheles gambiae binds to chitin. Cloning, expression, and characterization. J Biol Chem 1998, 273: $17665-17670$.

35. Peters W: Peritrophic membranes. Berlin, Springer-Verlag; 1992:238.

36. Briegel H: Fecundity, metabolism, and body size in Anopheles (Diptera: Culicidae), vectors of malaria. J Med Entomol 1990, 27:839-850

37. Fiil A: Structural and functional modifications of the nucleus during oogenesis in the mosquito Aedes aegypti. J Cell Sci 1974, 14:51-67.

38. Fiil A: Oogenesis in the malaria Mosquito Anopheles gambiae. Cell Tissue Res 1976, 167:23-35.

39. Sokolova MI: The reproductive history of female blood-sucking mosquitoes (Diptera, Culicidae). Med parazitol (Mosk) 1994, 2:

40. Gutzeit HO: The role of microfilaments in cytoplasmic streaming in Drosophila follicles. J Cell Sci 1986, 80:159-169.

41. Duffy JB, Perrimon N: The torso pathway in Drosophila: lessons on receptor tyrosine kinase signaling and pattern formation. Dev Biol 1994, 166:380-395.

42. Chang HC, Karim FD, O'Neill EM, Rebay I, Solomon NM, Therrien M, Wassarman DA, Wolff T, Rubin GM: Ras signal transduction pathway in Drosophila eye development. Cold Spring Harb Symp Quant Biol 1994, 59:147-153.

43. Seger R, Krebs EG: The MAPK signaling cascade. Faseb J 1995, 9:726-735.

44. Morisato D, Anderson KV: Signaling pathways that establish the dorsal-ventral pattern of the Drosophila embryo. Annu Rev Genet 1995, 29:37I-399.

45. Redfern CPF: 20-hydroxy-ecdysone and ovarian development in Anopheles stephensi. J Insect Physiol 1982, 28:97-109.

46. Snigirevskaya ES, Hays AR, Raikhel AS: Secretory and internalization pathways of mosquito yolk protein precursors. Cell Tissue Res 1997, 290:129-142.

47. Ahmed AM, Maingon R, Romans P, Hurd H: Effects of malaria infection on vitellogenesis in Anopheles gambiae during two gonotrophic cycles. Insect Mol Biol 200I, 10:347-356.

48. Hopwood JA Ahmed AM, Polwart A Williams GT, Hurd $\mathrm{H}$ : Malaria-induced apoptosis in mosquito ovaries: a mechanism to control vector egg production. J Exp Biol 200I, 204:2773-2780.

49. Holt RA, Subramanian GM, Halpern A, Sutton GG, Charlab R, Nusskern DR, Wincker P, Clark AG, Ribeiro JM, Wides R, Salzberg SL, Loftus B, Yandell M, Majoros WH, Rusch DB, Lai Z, Kraft CL, Abril JF, Anthouard V, Arensburger P, Atkinson PW, Baden H, de Berardinis V, Baldwin D, Benes V, Biedler J, Blass C, Bolanos R, Boscus D, Barnstead M, Cai S, Center A, Chaturverdi K, Christophides GK, Chrystal MA, Clamp M, Cravchik A, Curwen V, Dana A, Delcher A, Dew I, Evans CA, Flanigan M, Grundschober-Freimoser A, Friedli L, Gu Z, Guan P, Guigo R, Hillenmeyer ME, Hladun SL, Hogan JR, Hong YS, Hoover J, Jaillon O, Ke Z, Kodira C, Kokoza E, Koutsos A, Letunic I, Levitsky A, Liang Y, Lin J], Lobo NF, Lopez JR, Malek JA, McIntosh TC, Meister S, Miller J, Mobarry C, Mongin E, Murphy SD, O'Brochta DA, Pfannkoch C, Qi R, Regier MA, Remington K, Shao H, Sharakhova MV, Sitter CD, Shetty J, Smith TJ, Strong R, Sun J, Thomasova D, Ton LQ, Topalis P, Tu Z, Unger MF, Walenz B, Wang A, Wang J, Wang M, Wang X, Woodford KJ, Wortman JR, Wu M, Yao A, Zdobnov EM, Zhang H, Zhao Q, Zhao S, Zhu SC, Zhimulev I, Coluzzi M, della Torre A, Roth CW, Louis C, Kalush F, Mural RJ, Myers EW, Adams MD, Smith HO, Broder S, Gardner MJ, Fraser CM, Birney E, Bork P, Brey PT, Venter JC, Weissenbach J, Kafatos FC, Collins FH, Hoffman SL: The genome sequence of the malaria mosquito Anopheles gambiae. Science 2002, 298:129-149.

50. Shapiro AB, Wheelock GD, Hagedorn HH, Baker FC, Tsai LW, Schooley DA: Juvenile hormone and juvenile hormone esterase in adult females of the mosquito Aedes aegypti. I Insect Physiol 1986, 32:867-877. 
5I. Dubrovsky EB, Dubrovskaya VA, Berger EM: Juvenile hormone signaling during oogenesis in Drosophila melanogaster. Insect Biochem Mol Biol 2002, 32: I555-I565.

52. Muller HM, Crampton JM, della Torre A, Sinden R, Crisanti A: Members of a trypsin gene family in Anopheles gambiae are induced in the gut by blood meal. Embo ] 1993, I 2:289|-2900.

53. Barillas-Mury CV, Noriega FG, Wells MA: Early trypsin activity is part of the signal transduction system that activates transcription of the late trypsin gene in the midgut of the mosquito, Aedes aegypti. Insect Biochem Mol Biol 1995, 25:241-246.

54. Zinke I, Kirchner C, Chao LC, Tetzlaff MT, Pankratz MJ: Suppression of food intake and growth by amino acids in Drosophila: the role of pumpless, a fat body expressed gene with homology to vertebrate glycine cleavage system. Development 1999 , I 26:5275-5284.

55. Geering K: Haemolytic activity in the blood clot of Aedes aegypti. Acta Trop 1975, 32:|45-I5I.

56. Geering K, Freyvogel TA: Lipase activity and stimulation mechanism of esterases in the midgut of female Aedes aegypti. J Insect Physiol | 975, 2 I: | 25 |- | 256

57. Migeon JC, Garfinkel MS, Edgar BA: Cloning and characterization of peter pan, a novel Drosophila gene required for larval growth. Mol Biol Cell 1999, I 0:1733-I744.

58. Jackson SM, Berg CA: An A-kinase anchoring protein is required for protein kinase $A$ regulatory subunit localization and morphology of actin structures during oogenesis in Drosophila. Development 2002, I 29:4423-4433.

59. Gorjanacz M, Adam G, Torok I, Mechler BM, Szlanka T, Kiss I: Importin-alpha $\mathbf{2}$ is critically required for the assembly of ring canals during Drosophila oogenesis. Dev Biol 2002, 25 I:27I-282.

60. Robinson DN, Cooley L: Drosophila kelch is an oligomeric ring canal actin organizer. J Cell Biol 1997, I38:799-8I0.

61. Rohatgi R, Ma L, Miki H, Lopez M, Kirchhausen T, Takenawa T, Kirschner MW: The interaction between N-WASP and the Arp2/ 3 complex links Cdc42-dependent signals to actin assembly. Cell 1999, 97:221-231.

62. Murphy AM, Montell DJ: Cell type-specific roles for Cdc42, Rac, and RhoL in Drosophila oogenesis. / Cell Biol 1996, I33:617-630.

63. Cha BJ, Koppetsch BS, Theurkauf WE: In vivo analysis of Drosophila bicoid mRNA localization reveals a novel microtubule-dependent axis specification pathway. Cell 2001 , I 06:35-46.

64. Roth S, Neuman-Silberberg FS, Barcelo G, Schupbach T: cornichon and the EGF receptor signaling process are necessary for both anterior-posterior and dorsal-ventral pattern formation in Drosophila. Cell 1995, 81:967-978.

65. Schnorrer F, Bohmann K, Nusslein-Volhard C: The molecular motor dynein is involved in targeting swallow and bicoid RNA to the anterior pole of Drosophila oocytes. Nat Cell Biol 2000, 2:185-190.

66. Luk SK, Kilpatrick M, Kerr K, Macdonald PM: Components acting in localization of bicoid mRNA are conserved among Drosophila species. Genetics 1994, I37:521-530.

67. Xu T, Caron LA, Fehon RG, Artavanis-Tsakonas S: The involvement of the Notch locus in Drosophila oogenesis. Development 1992, I 15:913-922

68. Barolo S, Posakony JW: Three habits of highly effective signaling pathways: principles of transcriptional control by developmental cell signaling. Genes Dev 2002, I6: | |67-I |8|

69. Dollar G, Struckhoff E, Michaud J, Cohen RS: Rab I I polarization of the Drosophila oocyte: a novel link between membrane trafficking, microtubule organization, and oskar mRNA localization and translation. Development 2002, I 29:5। 17-526.

70. Mahone M, Saffman EE, Lasko PF: Localized Bicaudal-C RNA encodes a protein containing a KH domain, the RNA binding motif of FMRI. Embo J 1995, | 4:2043-2055.

7I. Saffman EE, Styhler S, Rother K, Li W, Richard S, Lasko P: Premature translation of oskar in oocytes lacking the RNA-binding protein bicaudal-C. Mol Cell Biol 1998, I 8:4855-4862

72. Hay B, Ackerman L, Barbel S, Jan LY, Jan YN: Identification of a component of Drosophila polar granules. Development 1988 , 1 03:625-640.

73. Verrotti AC, Wharton RP: Nanos interacts with cup in the female germline of Drosophila. Development 2000 127:5225-5232.
74. Dahanukar A, Wharton RP: The Nanos gradient in Drosophila embryos is generated by translational regulation. Genes Dev 1996, 10:2610-2620.

75. Gavis ER, Curtis D, Lehmann R: Identification of cis-acting sequences that control nanos RNA localization. Dev Biol 1996, 1 76:36-50.

76. Markussen FH, Michon AM, Breitwieser W, Ephrussi A: Translational control of oskar generates short OSK, the isoform that induces pole plasma assembly. Development 1995, | 2 1:3723-3732

77. Tomancak P, Guichet A, Zavorszky P, Ephrussi A: Oocyte polarity depends on regulation of gurken by Vasa. Development 1998 , I 25: | 723- I 732

78. Lieb B, Carl M, Hock R, Gebauer D, Scheer U: Identification of a novel mRNA-associated protein in oocytes of Pleurodeles waltl and Xenopus laevis. Exp Cell Res 1998, 245:272-28I.

79. Good PJ, Rebbert ML, Dawid IB: Three new members of the RNP protein family in Xenopus. Nucleic Acids Res 1993, 21:999-1006.

80. Vorbruggen G, Onel S, Jackle H: Restricted expression and subnuclear localization of the Drosophila gene Dnop5, a member of the Nop/Sik family of the conserved rRNA processing factors. Mech Dev 2000, 90:305-308.

81. Gonzalez-Reyes A, St Johnston D: The Drosophila AP axis is polarised by the cadherin-mediated positioning of the oocyte. Development 1998, I 25:3635-3644.

82. Chang HC, Rubin GM: 14-3-3 epsilon positively regulates Rasmediated signaling in Drosophila. Genes Dev 1997 I I: I |32-I I39.

83. Lopez-Girona A, Furnari B, Mondesert O, Russell P: Nuclear localization of Cdc25 is regulated by DNA damage and a 14-3-3 protein. Nature 1999, 397: I72-I75.

84. Schnorr JD, Holdcraft R, Chevalier B, Berg CA: Ras I interacts with multiple new signaling and cytoskeletal loci in Drosophila eggshell patterning and morphogenesis. Genetics 200I, I 59:609-622.

85. Renn SC, Tomkinson B, Taghert PH: Characterization and cloning of tripeptidyl peptidase II from the fruit fly, Drosophila melanogaster. J Biol Chem 1998, 273:19173-19182.

86. Mahajan R, Delphin C, Guan T, Gerace L, Melchior F: A small ubiquitin-related polypeptide involved in targeting RanGAPI to nuclear pore complex protein RanBP2. Cell 1997, 88:97-I07.

87. Desterro JM, Rodriguez MS, Hay RT: SUMO-I modification of IkappaBalpha inhibits NF-kappaB activation. Mol Cell 1998 , 2:233-239.

88. Bhaskar V, Valentine SA, Courey AJ: A functional interaction between dorsal and components of the Smt3 conjugation machinery. I Biol Chem 2000, 275:4033-4040.

89. Lehembre F, Badenhorst P, Muller S, Travers A, Schweisguth F, Dejean A: Covalent modification of the transcriptional repressor tramtrack by the ubiquitin-related protein Smt3 in Drosophila flies. Mol Cell Biol 2000, 20:1072-1082.

90. Johnson ES, Blobel G: Cell cycle-regulated attachment of the ubiquitin-related protein SUMO to the yeast septins. J Cell Biol 1999, | 47:981-994

91. Takahashi $Y$, lwase $M$, Konishi M, Tanaka M, Toh-e A, Kikuchi $Y$ : Smt3, a SUMO-I homolog, is conjugated to $\mathrm{Cdc3}$, a component of septin rings at the mother-bud neck in budding yeast. Biochem Biophys Res Commun I999, 259:582-587.

92. Fares H, Peifer M, Pringle JR: Localization and possible functions of Drosophila septins. Mol Biol Cell 1995, 6:1843-1859.

93. Vied C, Halachmi N, Salzberg A, Horabin Jl: Antizyme is a target of sex-lethal in the Drosophila germline and appears to act downstream of hedgehog to regulate sex-lethal and cyclin B. Dev Biol 2003, 253:214-229.

94. Carmena M, Riparbelli MG, Minestrini G, Tavares AM, Adams R, Callaini G, Glover DM: Drosophila polo kinase is required for cytokinesis. J Cell Biol 1998, I 43:659-67|

95. Becker S, Gehrsitz A, Bork P, Buchner S, Buchner E: The blackpearl gene of Drosophila defines a novel conserved protein family and is required for larval growth and survival. Gene 2001, 262:15-22

96. Kawamura K, Shibata T, Saget O, Peel D, Bryant PJ: A new family of growth factors produced by the fat body and active on Drosophila imaginal disc cells. Development |999, I26:2।|-219. 
97. Ron D, Mochly-Rosen D: Agonists and antagonists of protein kinase $\mathbf{C}$ function, derived from its binding proteins. J Biol Chem 1994, 269:21395-21398.

98. Liliental J, Chang DD: Rack I, a receptor for activated protein kinase C, interacts with integrin beta subunit. J Biol Chem 1998, 273:2379-2383.

99. Buensuceso CS, Woodside D, Huff JL, Plopper GE, O'Toole TE: The WD protein Rack I mediates protein kinase $C$ and integrindependent cell migration. J Cell Sci 200I, I I 4: I69 I-I698.

100. Cox EA, Bennin D, Doan AT, O'Toole T, Huttenlocher A: RACKI regulates integrin-mediated adhesion, protrusion, and chemotactic cell migration via its Src-binding site. Mol Biol Cell 2003, I 4:658-669.

10I. Mahairaki V, Lycett G, Blass C, Louis C: Beta-integrin of Anopheles gambiae: mRNA cloning and analysis of structure and expression. Insect Mol Biol 200I, I 0:217-223.

102. Edwards MJ, Severson DW, Hagedorn HH: Vitelline envelope genes of the yellow fever mosquito, Aedes aegypti. Insect Biochem Mol Biol 1998, 28:915-925.

103. Lin Y, Hamblin MT, Edwards MJ, Barillas-Mury C, Kanost MR, Knipple DC, Wolfner MF, Hagedorn HH: Structure, expression, and hormonal control of genes from the mosquito, Aedes aegypti, which encode proteins similar to the vitelline membrane proteins of Drosophila melanogaster. Dev Biol 1993, I 55:558-568.

104. Ferdig MT, Li J, Severson DW, Christensen BM: Mosquito dopa decarboxylase cDNA characterization and blood-mealinduced ovarian expression. Insect Mol Biol 1996, 5: I 19-126.

105. Johnson JK, Li J, Christensen BM: Cloning and characterization of a dopachrome conversion enzyme from the yellow fever mosquito, Aedes aegypti. Insect Biochem Mol Biol 200I, $31: 1125-1135$.

106. Cho KH, Raikhel AS: Organization and developmental expression of the mosquito vitellogenin receptor gene. Insect Mol Biol 200I, I 0:465-474

107. Cho WL, Tsao SM, Hays AR, Walter R, Chen JS, Snigirevskaya ES, Raikhel AS: Mosquito cathepsin B-like protease involved in embryonic degradation of vitellin is produced as a latent extraovarian precursor. J Biol Chem 1999, 274: I33।I-I332I.

108. Raikhel AS: Lysosomes in the cessation of vitellogenin secretion by the mosquito fat body; selective degradation of Golg complexes and secretory granules. Tissue Cell | 986, I 8: |25-|42.

109. Raikhel AS, Lea AO: Internalized proteins directed into accumulative compartments of mosquito oocytes by the specific ligand, vitellogenin. Tissue Cell I986, I 8:559-574.

I I0. Fabra M, Cerda J: Ovarian cysteine proteinases in the teleost Fundulus heteroclitus: molecular cloning and gene expression during vitellogenesis and oocyte maturation. Mol Reprod Dev 2004, 67:282-294.

I I I. Ribeiro JM: A catalogue of Anopheles gambiae transcripts significantly more or less expressed following a blood meal. Insect Biochem Mol Biol 2003, 33:865-882.

I 12. Brudno M, Chapman M, Gottgens B, Batzoglou S, Morgenstern B: Fast and sensitive multiple alignment of large genomic sequences. BMC Bioinformatics 2003, 4:66.

113. Sun LV, Chen L, Greil F, Negre N, Li TR, Cavalli G, Zhao H, Van Steensel B, White KP: Protein-DNA interaction mapping using genomic tiling path microarrays in Drosophila. Proc Natl Acad Sci U S A 2003, 100:9428-9433.

I 14. Rzhetsky A, lossifov I, Koike T, Krauthammer M, Kra P, Morris M, Yu H, Duboue PA, Weng W, Wilbur WJ, Hatzivassiloglou V, Friedman C GeneWays: a system for extracting, analyzing, visualizing, and integrating molecular pathway data. J Biomed Inform 2004 37:43-53.

I 15. Salazar CE, Mills-Hamm D, Kumar V, Collins FH: Sequence of a cDNA from the mosquito Anopheles gambiae encoding a homologue of human ribosomal protein S7. Nucleic Acids Res |993, 2 I:4|47.

1 16. Dimopoulos G, Richman A, della Torre A, Kafatos FC, Louis C: Identification and characterization of differentially expressed cDNAs of the vector mosquito, Anopheles gambiae. Proc Natl Acad Sci U S A 1996, 93: I3066-I307I.

I 17. Richman AM, Bulet P, Hetru C, Barillas-Mury C, Hoffmann JA, Kafalos FC: Inducible immune factors of the vector mosquito Anopheles gambiae: biochemical purification of a defensin antibac- terial peptide and molecular cloning of preprodefensin cDNA. Insect Mol Biol 1996, 5:203-2I0.

I 18. Richman AM, Dimopoulos G, Seeley D, Kafatos FC: Plasmodium activates the innate immune response of Anopheles gambiae mosquitoes. Embo J 1997, |6:6| |4-61।9.
Publish with Biomed Central and every scientist can read your work free of charge

"BioMed Central will be the most significant development for disseminating the results of biomedical research in our lifetime. "

Sir Paul Nurse, Cancer Research UK

Your research papers will be:

- available free of charge to the entire biomedical community

- peer reviewed and published immediately upon acceptance

- cited in PubMed and archived on PubMed Central

- yours - you keep the copyright 